\title{
Migración laboral en Nuevo León, México 1990-2015
}

\section{Labor migration in Nuevo Leon, Mexico 1990-2015}

\author{
Yuliet Bedoya Rangel* \\ Centro Regional de Investigaciones Multidisciplinarias (CRIM) \\ de la Universidad Nacional Autónoma de México, México
}

\section{Resumen}

El artículo presenta los cambios en la migración interna hacia Nuevo León utilizando como fuente primaria de información los microdatos censales de 1990-2010 y de la encuesta intercensal 2015 del Instituto Nacional de Estadística y Geografía (INEGI). Los principales resultados de esta investigación revelan que se ha presentado un aumento absoluto de los migrantes recientes que provienen principalmente de las entidades de San Luis Potosí, Tamaulipas, Veracruz y Ciudad de México, y aunque algunas de estas entidades son las que tradicionalmente han expulsado población a Nuevo León en los últimos años, no existe solamente un perfil migratorio, la globalización trajo consigo cambios en los procesos económicos nacionales y locales y la demanda de mano de obra se ha diversificado, por tanto, existen perfiles migratorios que se han adaptado a este cambio.

Palabras clave: Migración laboral, población, migrante interno, México, Nuevo León.

\begin{abstract}
The article presents the changes in internal migration to Nuevo León using the census microdata from 1990-2010 and the 2015 intercensal survey of the National Institute of Statistics and Geography (INEGI). The main results of this research reveal that there has been an absolute increase in recent migrants who come mainly from the entities of San Luis Potosí, Tamaulipas, Veracruz and Mexico City, and although some of these entities are those that have traditionally expelled population to Nuevo León in recent years, there is not only one migratory profile, globalization brought changes in national and local economic processes and the demand for labor has diversified, therefore, there are migratory profiles that have adapted to this change.
\end{abstract}

Keywords: Labor migration, population, internal migrant, Mexico, Nuevo León.

*Becaria del Programa de Becas Posdoctorales en el Centro Regional de Investigaciones Multidisciplinarias de la Universidad Nacional Autónoma de México (UNAM). Asesorada por el Dr. Fernando Lozano Ascencio.

Artículo recibido el 20 de agosto de 2020 y aprobado el 03 de noviembre de 2020. 


\section{INTRODUCCIón}

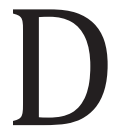

esde 1954, cuando Ravenstein promulgó las leyes de la migración, dejó claro que una de las principales causas de las migraciones ha sido la disparidad económica (Ravenstein, 1885). Para el caso de México, el impacto de la globalización en la economía nacional ha traído consigo regiones ganadoras y perdedoras, tanto en términos económicos como de población (Alba 1979; Chávez, 1999; Pérez, 2006). Según datos censales, en México "en 1940 había poco más de dos millones de personas viviendo en una entidad federativa distinta a la de su nacimiento. En 1992 se eleva la cantidad a $16.7 \mathrm{mi}-$ llones de personas (Chávez, 1999: 59). Ya para el 2015 la migración absoluta sumó 19.8 millones de personas (INEGI, 2015).

Pero no sólo la migración al interior de México ha cobrado protagonismo en las últimas décadas, Alba, (1979) explica que los trabajadores mexicanos cruzan la frontera con Estados Unidos en busca de trabajos temporales o migran definitivamente buscando mejores oportunidades. Según cifras del Consejo Nacional de población en el 2012 residían en el vecino país del norte alrededor de 11.9 millones de mexicanos (CONAPO, 2019).

Todos estos movimientos poblacionales cambian la estructura y dinámica económica de México. "La actividad económica se distribuyó en el territorio en función del aprovechamiento de economías de aglomeración que ofrecía el espacio, propiciándose, al mismo tiempo, una reestructuración sectorial conforme el país avanzaba en su grado de urbanización" (Sobrino, 2010: 38).

La entidad de Nuevo León no ha escapado a esta realidad, estudios recientes han demostrado que uno de los principales incentivos de la migración interna hacia Nuevo León ha sido el empleo y los niveles de desarrollo humano que ofrece la entidad (Valero y Tijerina, 1998; Sánchez et al., 2014).

El objetivo de este artículo es conocer cómo han cambiado los perfiles sociodemográficos y laborales de los migrantes internos que llegaron a Nuevo León entre 1990 y 2015 y cómo estos flujos migratorios han sido "absorbidos" por el mercado laboral de la entidad. 
El artículo se divide en cuatro partes. Primero se presenta el estado de la cuestión, luego se resume la metodología utilizada en esta investigación, para pasar al tercer apartado que contiene los resultados, donde a manera de contexto se presentarán la evolución demográfica y económica de Nuevo León, las tasas de migración, el origen y las principales causas de migración, para luego analizar las características propias del migrante: la estructura por sexo y edad, la educación con que llegan al Estado, relacionando lo anterior con su situación laboral. En la cuarta parte, se presentan las conclusiones de esta investigación.

\section{MARCo CONCEPTUAL DE LA MIGRACIÓN INTERNA}

Las teorías migratorias se han ido enriqueciendo a lo largo de los años desde diversos enfoques, unas con mayor trascendencia que otras, pasando de explicaciones teóricas meramente económicas (Ravenstein, 1885; Lewis, 1960; Lee, 1966; Todaro, 1982; Castles y Kosack, 1984), a explicar la migración desde perspectivas integradoras como el capital social, las relaciones sociales y la calidad de vida (Gurak y Caces, 1998; Massey, 1990; Stark, 1993; Faist, 2010, Alarcón, 2001; Canales, 2015).

Desde la teoría de la migración de Lee (1966) los flujos laborales de migrantes son el resultado de las condiciones económicas, políticas y sociales adversas en el lugar de origen, que actúan como una fuerza de expulsión, que combinadas con factores de atracción (mejores salarios, mayores oportunidades, estabilidad política y social) determinan las olas migratorias.

Por otra parte, desde la nueva economía, Stark destaca la importancia que tiene la familia del migrante en la causa de la migración y la perpetuación de estos movimientos poblacionales. Para el autor "la migración de los miembros de una familia se puede interpretar como una manifestación de la viabilidad de la familia" (Stark, 1993: 16) donde se comparten costos y recompensas. El autor no considera a la familia como una entidad que se divide cuando sus miembros más jóvenes buscan independencia tratando de desligarse de vínculos familiares, sino que considera la migración como "estrategia calculada" y no como un acto de desesperación y optimismo sin límites.

En este sentido Stark (1993) expone que "una fuerte dependencia del capital, de redes y de parientes es otra característica destacada de los modelos de comportamiento de los migrantes" (p. 41). Esta teoría es apoyada por Portes y Böröcz (1998) quienes aseveran en sus investigaciones que "el inicio de flujo de mano de obra no tiene su origen en 
las comparaciones celosas de ventajas económicas, sino en una historia de contactos previos entre las sociedades emisoras y receptoras" (p. 45). Estas redes sociales tienen incidencia directa en los itinerarios migratorios y procesos de inserción social y laboral, que pueden ser selectivos dependiendo del lugar de origen del migrante.

En esta investigación se define migrante a "toda persona cuya división territorial de residencia al inicio de un periodo de observación difiere de la división territorial de residencia al final de dicho periodo" (Macció, 1985: 120). Migrante interno se refiere a aquellas personas que se movieron dentro del territorio nacional, en este estudio son todos aquellos que se movieron a Nuevo León. De modo que los migrantes internos serán analizados creando perfiles que dependerán de sus características sociodemográficas y sus lugares de origen.

Para entender los cambios en los flujos migratorios de los últimos veinticinco años hacia Nuevo León, se estudiará la selectividad migratoria. La cual puede definirse como el sesgo de los migrantes en una o más características. No hay selectividad migratoria cuando el perfil de los migrantes es igual al de la población no migrante. Rodríguez (2016) explica que existe una condición matemática de no selectividad migratoria y que corresponde al caso en que la distribución por un atributo (estructura) de los migrantes coincide con la distribución territorial del "resto" (o de los no migrantes).

\section{ANTECEDENTES SOBRE LA MIGRACIÓN INTERNA EN MÉXICO}

Hace ya cuarenta años Alba (1979) explicaba que las desigualdades regionales en el orden económico, social, político y de recursos, se encontraban en la base de este movimiento poblacional mexicano interno.

Entre 1940 y 1960, y a nivel de entidad federativa, la población que migra ha tendido a hacerlo al Distrito Federal y hacia el Norte; a los estados fronterizos de Baja California, Chihuahua, Nuevo León y Tamaulipas. En ocho entidades se localizaba el 65.2 por ciento del total de la población inmigrante en 1940, el 69.8 por ciento en 1950 y el 71 por ciento en 1960 (Alba, 1979: 82).

De 1970 al 2005 la pertenencia regional de las principales entidades de emigración establece que las regiones Occidente y Sur-Sureste fueron, después de la ciudad de México, las áreas predominantes de salida de población. Los grandes flujos de migración reciente tuvieron 
como origen la Ciudad de México y el Occidente y Sur-Sureste del país, en tanto que el destino fue hacia las metrópolis más pobladas del país y a las entidades de la Frontera Norte (Sobrino, 2010: 69).

En cuanto a la distancia geográfica, Partida (1994) demuestra que el trayecto en los movimientos de población al interior del país pasan a segundo término cuando existe un buen atractivo en el potencial lugar de destino, sin importar que medien cientos de kilómetros para realizar el desplazamiento de la residencia. Estos desplazamientos son facilitados por las redes sociales que los migrantes construyen a través del tiempo y el espacio.

Los estudios demuestran que las oleadas migratorias del campo a la ciudad en México se han transformado en nuevos flujos entre ciudades, evidenciando el menor ritmo de crecimiento de las grandes metrópolis y la emergencia de ciudades intermedias. Pérez y Santos (2008) aseveran que las zonas metropolitanas que presentan mayor atracción son: Tijuana (109 027 migrantes), Juárez (97 847 migrantes), Cancún (68 583 migrantes), Monterrey (57 059 migrantes), Reynosa-Río Bravo (47 377 migrantes) y Querétaro (39 973 migrantes). Concluyen los autores que estos movimientos poblacionales están influenciados directamente por el cambio en la distribución tanto de las actividades económicas como de la población en México.

En este mismo sentido, Sobrino (2016) relaciona estos movimientos poblacionales con transiciones en el curso de vida de los migrantes principalmente con el fin de la formación educativa y el ingreso al mercado de trabajo. El autor demuestra cómo la tasa de migración de la población con primaria completa fue de alrededor de seis por ciento, en tanto que los egresados de alguna licenciatura o posgrado tuvieron una tasa de más de 15 por ciento. De modo que el curso de vida sobre la formación académica de grado y posgrado corresponde con mayor tasa de migración de mexicanos.

Estos estudios a nivel nacional permiten visibilizar las nuevas dinámicas de la migración interna en México. Para el caso de Nuevo León el desarrollo económico de la entidad ha consolidado un mercado de trabajo heterogéneo que demanda mano de obra en todos los sectores económicos que llegan de todas partes del país, por lo que es indispensable conocer las características sociodemográficas de la población migrante, así como cambios en la situación laboral de los inmigrantes en relación con los nativos. 


\section{METODOLOGÍA Y FUENTES DE INFORMACIÓN}

Esta investigación toma como punto de partida la hipótesis de que, la población migrante que llega a Nuevo León de otras entidades federativas se encuentra en segmentos de edad vinculados a la inserción laboral. Sus características han cambiado en los últimos veinticinco años, la selectividad de migrantes ha dependido de los cambios en los sectores de inserción laboral.

Las bases de datos utilizadas fueron las muestras censales de 1990, 2000 y 2010, así como los de la Encuesta Intercensal 2015, cada una de las cuales contienen información por entidad federativa sobre las características sociodemográficas básicas, el tamaño, la composición y la distribución territorial de la población en el país. En cuanto al análisis de las causas de la migración hacia Nuevo León, se tomaron datos del Censo General de Población y Vivienda del año 2000 y la Encuesta de la Dinámica Migratoria de 2014.

La medición directa de la migración permite captar el lugar de residencia previo, diferente a aquel donde vivía el individuo al momento del recuento. Hay dos preguntas que en los cuestionarios censales permiten conocer la migración: el lugar de nacimiento y el lugar de residencia anterior cinco años antes; ambas preguntas se comparan con el lugar de residencia actual, para así identificar al migrante (sea migrante de toda la vida o migrante reciente). Al ser iguales se asume que no hay migración y si difieren significa que ha habido migración. En este esta investigación se analizan los migrantes recientes que llegaron a Nuevo León provenientes de otras entidades federativas mexicanas entre 1990 y 2015.

Al estudiar la migración a Nuevo León, se analizaron los cambios en los volúmenes y las características de los migrantes (volumen de migración, edades, sexo, escolaridad y otros datos demográficos), los cuales evidenciaron perfiles migratorios en diferentes décadas (19902015) y selectividad migratoria. Para esto se utilizaron procedimientos estadísticos que parten de lo descriptivo y algunos análisis bivariados.

Para conocer la disimilitud que pueda existir en la participación de los migrantes en el mercado laboral de Nuevo León, se aplicó el índice de Disimilitud de Duncan ${ }^{1}$ (1955), el cual es el resultado de la dife-

$1 \quad D$ es nulo cuando el cociente entre población minoritaria y la total en cada subdivisión es una constante. No hay segregación o no hay selectividad. $D$ es máximo (1) cuando la minoría reside o clasifica en una o más divisiones o categorías sin representantes de la mayoría (resto de la población). 
rencia entre la estructura de los migrantes y de los no migrantes en la variable de selectividad, que en este caso se refiere a las ocupaciones.

Ecuación 1. Índice de Disimilitud de Duncan

$$
D=\frac{1}{2} \sum\left|\frac{N_{1 i}}{N_{1}}-\frac{N_{2 i}}{N_{2}}\right|
$$

Definiciones:

- $\mathrm{N}_{1}$ Población migrante total.

- $\mathrm{N}_{1 \mathrm{i}}$ Población migrante en la categoría $i$ de la variable de caracterización.

- $\mathrm{N}_{2}$ Población no migrante total.

- $\mathrm{N}_{2 \mathrm{i}}$ Población no migrante en la categoría $i$ de la variable de caracterización. ${ }^{2}$

En el análisis también se describe cual es el efecto de diferentes variables (lugar de origen, sexo y escolaridad) en la selectividad migratoria laboral que se pueda presentar en Nuevo León. Para no perder la representación en este análisis, se crearon cuatro grandes grupos de ocupaciones:

No manual de alta calificación: funcionarios y directivos, jefes administrativos, jefes y supervisores de fabricación, profesionales, técnicos, trabajadores de la educación, trabajadores del arte, espectáculo y deporte.

No manual de baja calificación: trabajadores auxiliares en actividades administrativas, comerciantes y vendedores.

Manual de alta calificación: operadores de maquinaria fija y equipos industrial, operadores de transporte, obreros y artesanos.

Manual de baja calificación: trabajadores agropecuarios, ayudantes, peones y similares, trabajadores ambulantes, trabajadores domésticos, trabajadores en servicios personales, trabajadores en protección.

$\overline{2}$ Fuente: Manual de Migración, CEPAL División de Población, 2016. 


\section{RESULTADOS}

\section{Nuevo León, evolución demográfica y económica}

Nuevo León, está ubicado al noreste de México, ocupa 3.3 por ciento del territorio nacional, con $64,156 \mathrm{~km}^{2}$ de extensión y es fundado en 1596. La evolución demográfica de Nuevo León ha sido lenta, "durante el siglo XVII apenas sobrevivió, pues sufrió dos grandes inundaciones en 1611 y 1936, la última de las cuales arrasó con todas las edificaciones, cuya reconstrucción emprendieron pacientemente alrededor de doscientas personas" (Garza, 1999: 21).

El crecimiento poblacional de Nuevo León no ha sido uniforme, a principios del siglo XX la intensificación de la Revolución y la inestabilidad política y social de México fueron razones para que miles de sus habitantes migraran a Estados Unidos. El Censo General de Habitantes 1921, reportó 336,412 habitantes, reportando un crecimiento negativo de -7.8 por ciento (Figura 1 ).

Figura 1. Crecimiento poblacional en Nuevo León 1895-2015

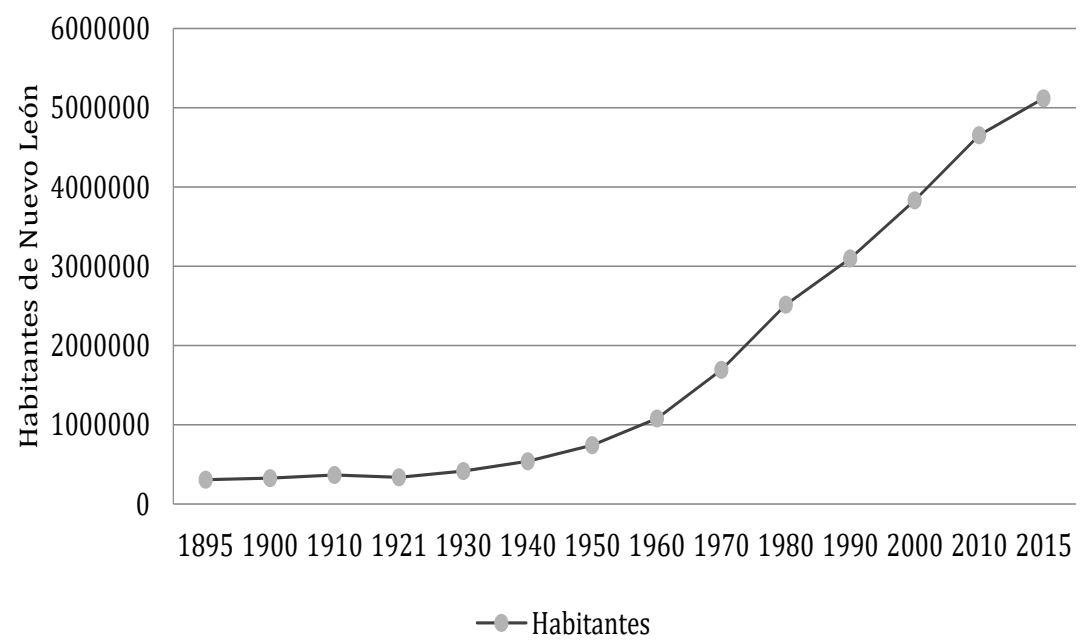

Fuente: Elaboración propia datos de 1895 a 1970 Documento Aspectos demográficos del estado de Nuevo León y de 1980-2015 datos censales del INEGI

A partir de 1921, y hasta 1940, la población tiene un crecimiento sostenido. A inicios del siglo XX Nuevo León contaba con 327,937 ha- 
bitantes, y en 1970 su población ascendía a 1'694,689 habitantes, es decir, en 70 años su población se incrementó 417 por ciento (Figura 1).

Los cambios económicos y sociales que se dieron en Nuevo León a partir de 1940, coincidente con el llamado "milagro mexicano" por las altas tasas de crecimiento económico y financiero, estimulando flujos migratorios que, sumados al crecimiento natural de la población, acentuaron el crecimiento demográfico (Ortega, 2007; Contreras, 2010).

Ortega afirma que la consolidación industrial de Monterrey tuvo como pilares productos ya tradicionales: "acero, cemento, vidrio y cerveza, sumándose nuevas ramas como la automotriz, el tabaco y los productos químicos" (Ortega, 2007).

Este cambio económico estructural de Nuevo León modificó su expansión urbana. Además, de esto se vio la necesidad de capacitar la mano de obra de la región por lo que se crearon centros de estudios técnicos y profesionales, "La Universidad Autónoma de Nuevo León, creada en 1933 y reabierta en 1943, se unió ese año el Instituto Tecnológico y de Estudios Superiores de Monterrey, ahora llamado Tecnológico de Monterrey fueron la principal oferta educativa a fines de los sesenta" (Ortega, 2007: 17).

De modo que de 1990 al 2010 hubo un incremento de población en Nuevo León de 22 por ciento en promedio por década, llegando a alcanzar en 2010 un monto poblacional de 4653458.

Balán y Jelín (1973) en su estudio "Migración a Monterrey y movilidad social" consideraron que Monterrey tuvo un crecimiento económico en las últimas décadas muy superior al promedio de las ciudades latinoamericanas, que ha ofrecido condiciones favorables y flexibles de desarrollo a los migrantes (p. 240).

La Figura 2 presenta dos variables que permiten analizar la dinámica económica de Nuevo León: el porcentaje de migrantes recientes del total de la población de Nuevo León y el porcentaje del PIB Nacional de Nuevo León ambos de 1970 a 2015.

En 1970, el protagonismo de los migrantes llegó a 8.4 por ciento de la población total. De 1990 a 2015 la migración reciente se ha mantenido en entre tres y cuatro por ciento de la población, configurando nuevos perfiles migratorios. Perfiles que serán descritos más adelante.

El crecimiento del Producto Interno Bruto estatal ha sido constante y la atracción de población de otras entidades se ha mantenido. Nuevo León ha tenido la capacidad de aumentar su contribución al PIB nacio- 
nal década tras década, pasando de generar 5.9 por ciento en 1990 a 7.1 por ciento en 2010 (Figura 2).

Figura 2. Porcentaje de contribución al PIB nacional de Nuevo León y porcentaje de migrantes recientes del total de la población

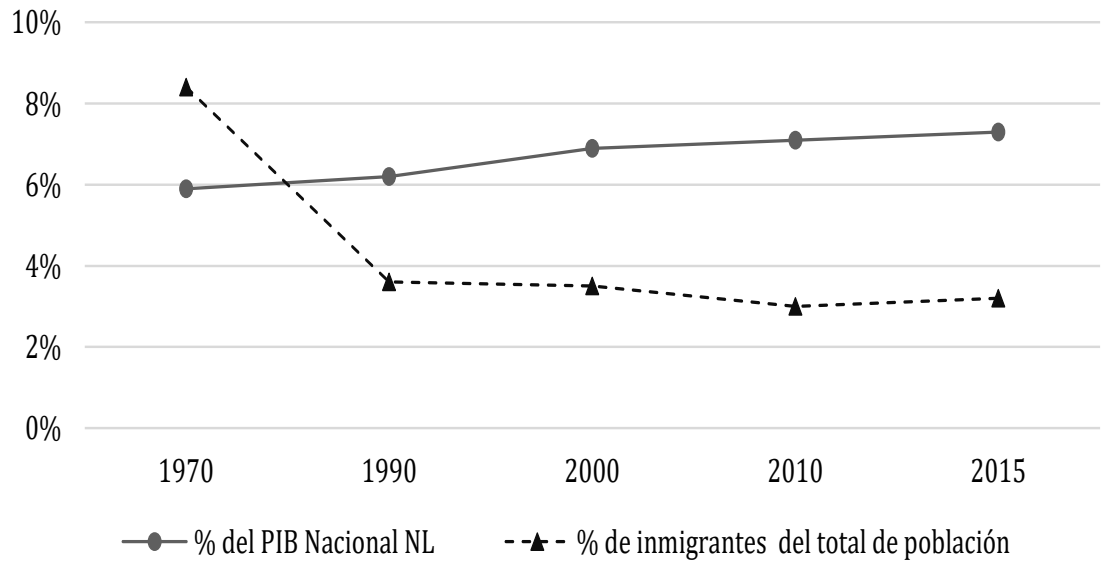

Fuente: Porcentaje de migrantes, elaboración propia con base en datos censales 1970, 1990, 2010 y Encuesta Intercensal 2015. PIB (1970-2000) datos recuperados de Soto 2005 y PIB (2010-2015) datos del Sistema de Cuentas Nacionales de México, INEGI.

Para 2015, Nuevo León con 4.3 por ciento de la población nacional generó 7.3 por ciento del PIB nacional, y es que la apertura comercial que ha tenido la entidad en los últimos diez años se ve reflejada en su productividad y el cambiado de su perfil productivo, emergiendo servicios de alto valor agregado como los financieros, salud, educación y cultura. El crecimiento económico ha jugado un doble papel, ha permitido que la población nativa encuentre en Nuevo León condiciones favorables para quedarse y además ha incentivado que personas de otras entidades lleguen a asentarse y a desarrollar sus proyectos familiares en la entidad.

\section{Cifras de la migración interna en Nuevo León}

A nivel nacional, en los últimos 25 años es el Estado de México y Ciudad de México quienes han absorbido la mayor cantidad de migrantes internos (Tabla 1). 
Tabla 1. Migrantes internos en las entidades federativas mexicanas 1990 - 2015

\begin{tabular}{|c|c|c|c|}
\hline Entidad & 1990 & Entidad & 2000 \\
\hline México & 786,367 & México & 649,950 \\
\hline Ciudad de México & 298,235 & Ciudad de México & 359,178 \\
\hline Baja California & 220,564 & Baja California & 212,042 \\
\hline Jalisco & 178,011 & Jalisco & 151,619 \\
\hline Veracruz & 163,586 & Tamaulipas & 148,146 \\
\hline Puebla & 125,686 & Veracruz & 138,300 \\
\hline Chihuahua & 118,079 & Chihuahua & 135,070 \\
\hline Tamaulipas & 115,296 & Puebla & 128,184 \\
\hline Nuevo León & 113,844 & Nuevo León & 123,871 \\
\hline Michoacán & 105,602 & Quintana Roo & 106,330 \\
\hline Guanajuato & 98,419 & Guanajuato & 87,364 \\
\hline Quintana Roo & 92,810 & Morelos & 83,614 \\
\hline Morelos & 91,227 & Sinaloa & 83,480 \\
\hline Sinaloa & 82,811 & Hidalgo & 82,046 \\
\hline Oaxaca & 73,892 & Michoacán & 78,720 \\
\hline Sonora & 72,121 & Querétaro & 78,652 \\
\hline Coahuila & 69,194 & Sonora & 75,785 \\
\hline Querétaro & 67,857 & Coahuila & 70,155 \\
\hline Hidalgo & 66,964 & Oаxaca & 60,195 \\
\hline San Luis Potosí & 64,399 & San Luis Potosí & 50,898 \\
\hline Otros & 463,544 & Otros & 458,401 \\
\hline Tabasco & 47,815 & Guerrero & 50,877 \\
\hline Guerrero & 46,617 & Chiapas & 45,240 \\
\hline Aguascalientes & 43,979 & Yucatán & 44,554 \\
\hline Chiapas & 42,322 & Tabasco & 43,815 \\
\hline Durango & 41,148 & Aguascalientes & 42,439 \\
\hline Yucatán & 38,364 & Baja California Sur & 37,189 \\
\hline Zacatecas & 36,554 & Durango & 36,859 \\
\hline Nayarit & 35,865 & Nayarit & 36,772 \\
\hline Tlaxcala & 35,858 & Campeche & 33,873 \\
\hline Campeche & 34,459 & Tlaxcala & 32,272 \\
\hline Colima & 31,103 & Colima & 30,741 \\
\hline Baja California Sur & 29,460 & Zacatecas & 23,770 \\
\hline
\end{tabular}
Intercensal 2015.

Son las desigualdades económicas, los mejores salarios y el acceso a bienes y servicios en México lo que hace que los migrantes busquen al interior del país oportunidades para su desarrollo y de su familia (Partida, 1994; Chávez, 1999). En 1990 Nuevo León ocupó el puesto nueve a nivel nacional con 113844 inmigrantes, en 2015 llegan a Nuevo León 162525 personas, convirtiendo la entidad en la cuarta con mayor número de inmigrantes. 
Tabla 1. Continuación

\begin{tabular}{lrlr}
\hline Entidad & 2,010 & Entidad & 2,015 \\
\hline México & 583,607 & México & 494,631 \\
Ciudad de México & 239,125 & Ciudad de México & 319,108 \\
Veracruz & 206,240 & Veracruz & 170,846 \\
Jalisco & 160,853 & Nuevo León & 162,525 \\
Baja California & 154,029 & Jalisco & 155,057 \\
Quintana Roo & 143,899 & Baja California & 141,968 \\
Nuevo León & 133,657 & Puebla & 135,294 \\
Puebla & 130,190 & Quintana Roo & 132,179 \\
Hidalgo & 122,511 & Querétaro & 123,761 \\
Tamaulipas & 106,410 & Hidalgo & 118,317 \\
Querétaro & 94,336 & Guanajuato & 87,767 \\
Guanajuato & 91,456 & Sinaloa & 81,339 \\
Oaxaca & 84,534 & Morelos & 75,318 \\
Michoacán & 79,866 & Oaxaca & 72,571 \\
Morelos & 78,610 & Sonora & 69,784 \\
Sonora & 78,545 & Tamaulipas & 69,266 \\
Baja California Sur & 73,920 & Michoacán & 64,279 \\
Sinaloa & 73,573 & Yucatán & 60,562 \\
Nayarit & 62,708 & Coahuila & 60,342 \\
Coahuila & 61,636 & Baja California Sur & 55,813 \\
Otros & 532,605 & Otros & 506,948 \\
Chihuahua & 58,334 & Chiapas & 53,327 \\
San Luis Potosí & 57,368 & Chihuahua & 50,611 \\
Guerrero & 53,193 & Nayarit & 49,331 \\
Chiapas & 50,571 & San Luis Potosí & 48,697 \\
Yucatán & 49,815 & Campeche & 43,915 \\
Colima & 41,483 & Guerrero & 42,878 \\
Aguascalientes & 41,061 & Tabasco & 42,865 \\
Tabasco & 39,263 & Aguascalientes & 42,143 \\
Durango & 39,200 & Colima & 39,504 \\
Tlaxcala & 38,100 & Tlaxcala & 36,415 \\
Campeche & 33,895 & Durango & 32,390 \\
Zacatecas & 30,322 & Zacatecas & 24,872 \\
Fuente: elaboración propia & con ense en microdatos censales, 1990, 2000, 2010 y Encuesta \\
Intercensal 2015 & & &
\end{tabular}

Las tasas de migración expresan el efecto de la inmigración o emigración en la variación de la población de Nuevo León, ocurrida en los cinco años previos al censo. La tasa de inmigración reciente relaciona el total de personas que llegan a vivir a Nuevo León respecto a las personas que residen en la entidad. Mientras que la tasa de emigración reciente relaciona el total de personas que emigran de Nuevo León respecto a las personas que residen en la entidad. Los datos revelan que se presenta una desaceleración en la tasa de inmigración de 1990 a 2010 en la entidad, pero en 2015 la tasa se recupera elevándose a 7.15 , lo que indica que Nuevo León incrementó su población inmigrante en siete habitantes por cada mil. La baja que refleja la tasa de emigración revela una pérdida de casi cinco habitantes por cada mil 
en 1990, pero la cifra se recupera llegando a 2010 a 3.8 personas emigrantes por cada mil.

La intensidad migratoria es evaluada por la tasa neta de migración, esta representa el efecto neto de la inmigración y la emigración de la población de Nuevo León, expresando una ganancia o pérdida de población, durante los últimos cinco años previos al censo.

Los datos revelan que Nuevo León ha tenido una ganancia contante de población por efecto de la migración y llega a 2015 con una tasa de 1.97 personas por cada mil habitantes, presentado un balance migratorio positivo (Figura 3).

Figura 3. Tasas de migración en Nuevo León 1990 - 2015

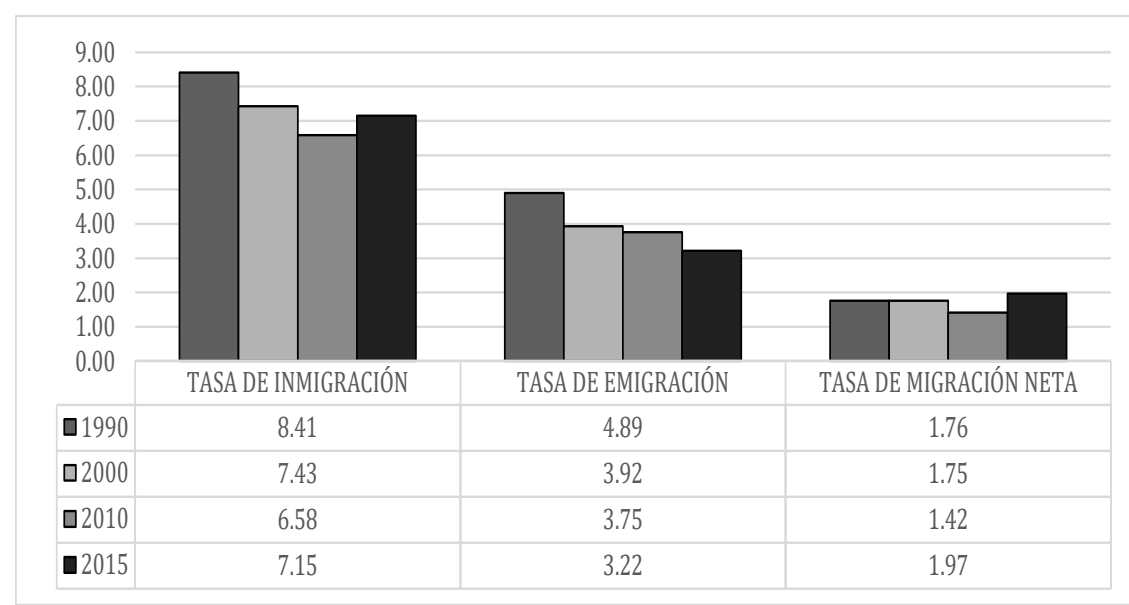

Fuente: elaboración propia con base en microdatos censales, 1990, 2000, 2010 y Encuesta Intercensal 2015.

\section{Origen de los migrantes internos que llegan a Nuevo León de 1990-2015}

Se considera en esta investigación que un factor intrínseco del proceso de migración interna es la distancia, y es que la migración hacia Nuevo León ha estado protagonizada principalmente por las entidades federativas vecinas, aunque se han venido configurando nuevas corrientes migratorias en los últimos años; por lo que se hace indispensable conocer el lugar de residencia anterior de los migrantes que arribaron a Nuevo León de 1990 a 2015.

Para 1990, Tamaulipas con 21.2 por ciento fue la entidad que más expulsó población hacia Nuevo León, seguido de San Luis Potosí 16.3 
por ciento y Coahuila con 15.2 por ciento. También empiezan a tener protagonismo en expulsión de población hacia Nuevo León las entidades de Ciudad de México, Zacatecas y Veracruz (Tabla 2). Los cambios relacionados o impulsados con el desarrollo, como son el incremento en las vías y medios de comunicación y transporte acortaron las distancias, incrementando la posibilidad de trasladarse casi desde cualquier punto geográfico del país por alejado que se encuentre, esto ha permitido que arriben a Nuevo León migrantes internos originarios de entidades federativas alejadas diversificándose los lugares de origen.

Al igual que en 1990 del total de movimientos migratorios hacia Nuevo León, el censo del año 2000 revela que el 17.5 por ciento de los migrantes que llegan a Nuevo León provienen de Tamaulipas y 16.5 por ciento de San Luis Potosí. Sobresale para este periodo una diversificación mayor por lugar de origen del migrante reciente.

La Tabla 2 muestra que para el año 2010, entidades como Veracruz ganan más protagonismo representando el 13.9 por ciento de la población que arribo a Nuevo León, seguido por Coahuila 10.7 por ciento y Ciudad de México 6.8 por ciento. Sobrino (2010) explicaba que en los últimos treinta años en México se ha dado una mayor propensión de los movimientos migratorios hacia entidades no vecinas, esto como producto del cambio en la tipología migratoria ocurrida durante este periodo y caracterizada por un mayor peso de la migración urbana-urbana con respecto a la rural-urbana.

El censo de 2010 revela que 60 de cada 100 migrantes provienen de San Luis Potosí, Tamaulipas, Veracruz, Coahuila y Ciudad de México. Comparando con años anteriores aumenta la representación de migrantes provenientes del Estado de México con cinco por ciento e Hidalgo con 4.8 por ciento (Tabla 2).

La Encuesta Intercensal 2015 refleja una realidad completamente distinta a lo que se veía en el censo de 1990, y es que la procedencia del migrantes que llega a Nuevo León es cada vez más variada.

La diversificación económica y la oferta de vivienda y de servicios públicos que Nuevo León ha tenido en los últimos 20 años ha permitido atraer población de todas partes del país. De manera tradicional la mayor proporción de migrantes en Nuevo León eran originarios de entidades contiguas geográficamente como: Tamaulipas, San Luis Potosí, Coahuila y Zacatecas. Pero en los últimos 25 años se consolidaron algunos flujos migratorios no tradicionales como son los conformados por migrantes originarios de Veracruz, Hidalgo y México (Tabla 2). Es- 
tudios recientes a nivel nacional explican que el peso de la distancia en la migración ha cambiado, los medios de transporte y de comunicación, así como el desarrollo de infraestructura vial y la tecnología en México parecen facilitar la movilidad a lugares no tan cercanos (Sobrino, 2010; Pérez y Santos, 2013).

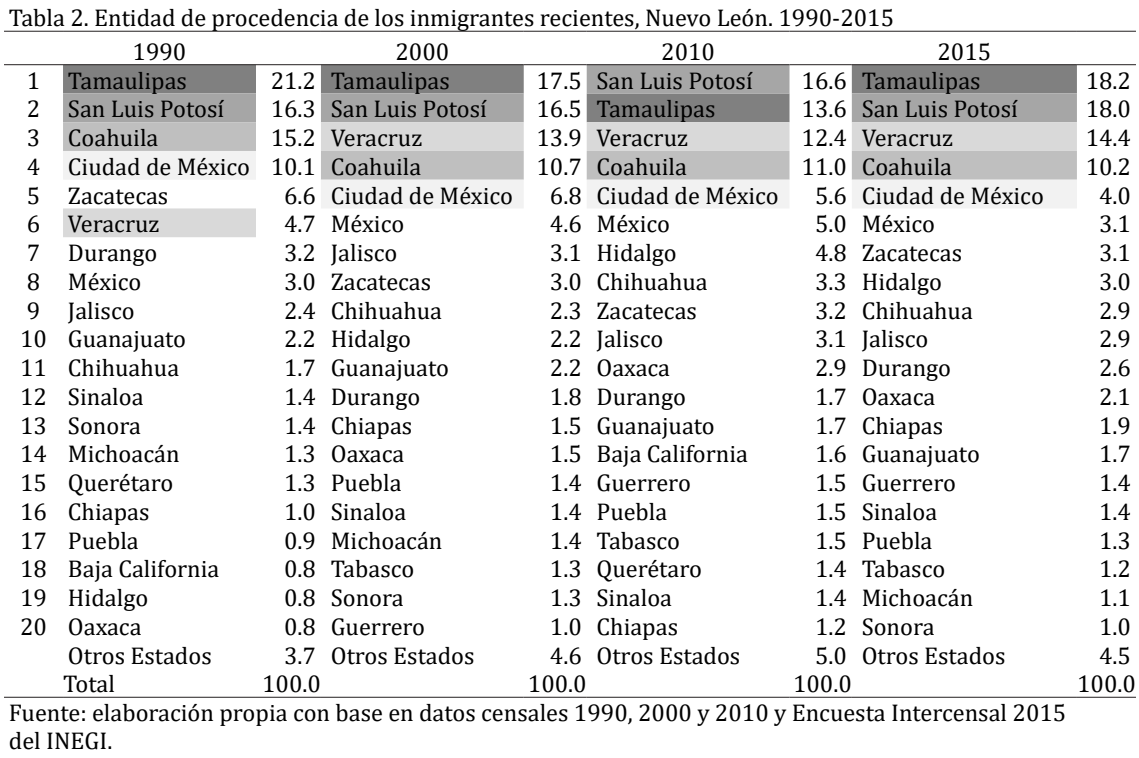

\section{Causas de la migración}

Las causas de la migración no han sido indagadas en todos los censos o encuestas que comprenden el periodo 1990-2015, esta información solo ha sido recogida en el censo del año 2000 y en la Encuesta de Dinámica Demográfica 2014. A continuación, se presentan las principales causas por las que los migrantes han llegado a Nuevo León (Figuras 4 y 5 ).

Aunque la migración hacia Nuevo León no ha tenido una preponderancia masculina o femenina en las últimas décadas, las causas son distintas, y es que las causas laborales en los hombres rebasan 50 por ciento de las causas mencionadas para migrar, seguida por la reunificación familiar (18.6 por ciento) y la oportunidad de estudiar (14.3 por ciento). 
Figura 4. Causas de migración de población de otras entidades hacia Nuevo León, año 2000

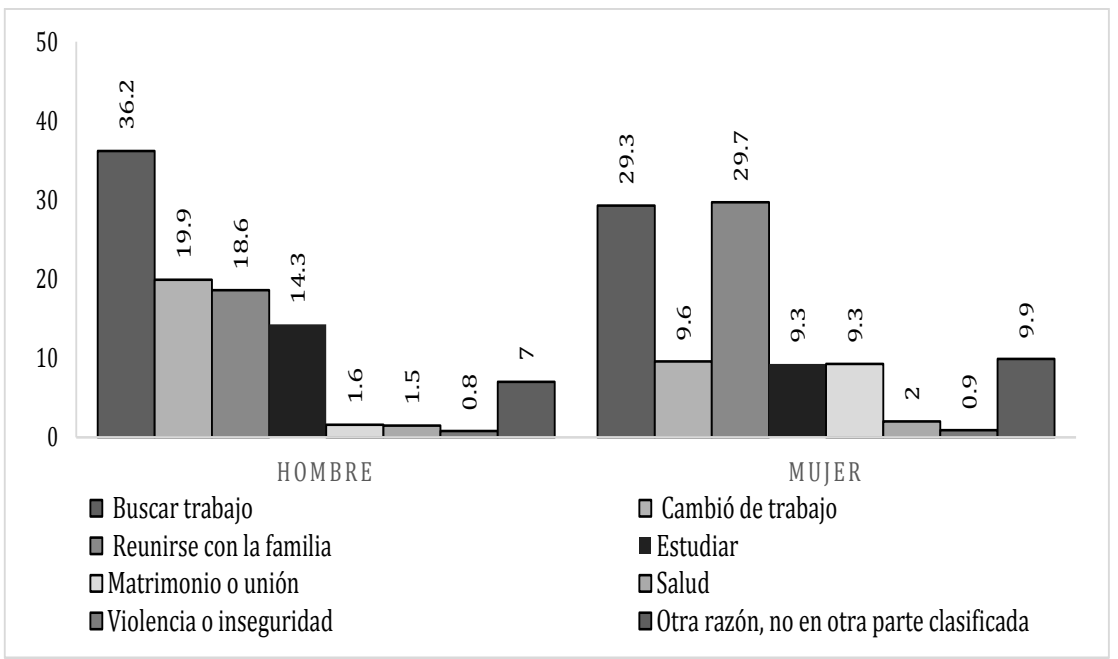

Fuente: elaboración propia con base en microdatos del XII Censo general de Población y Vivienda del año 2000.

Figura 5. Causas de migración de población de otras entidades a Nuevo León, año 2014

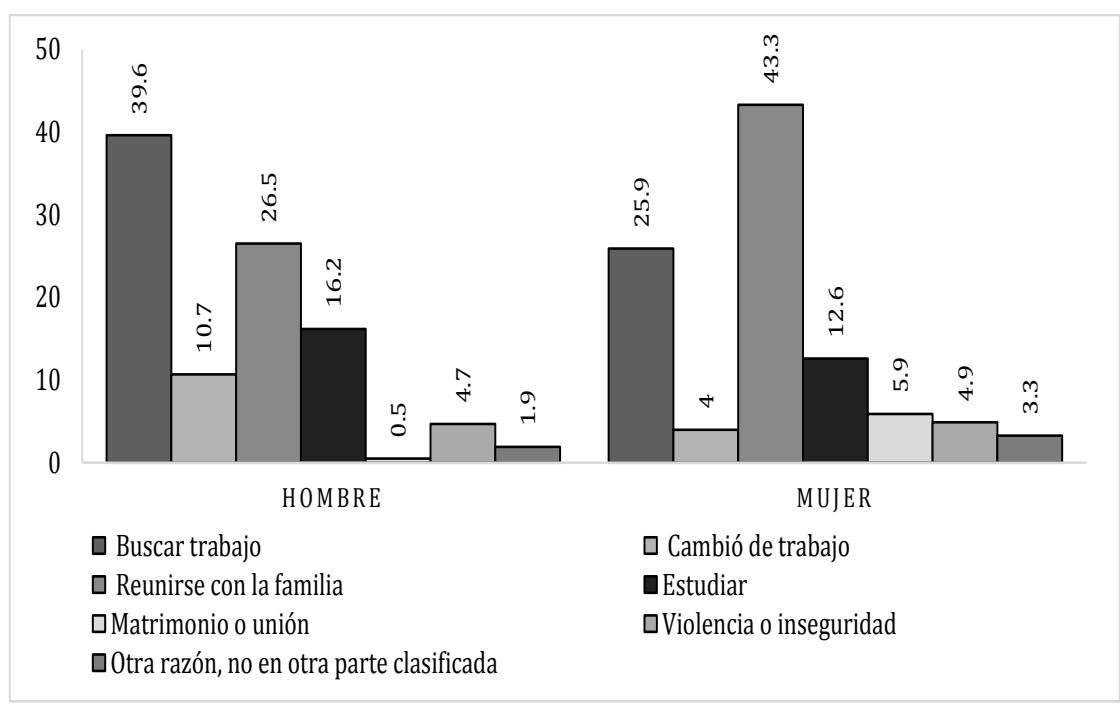

Fuente: elaboración propia con base en microdatos de la Encuesta de la Dinámica Migratoria del 2014. 
Mientras que las mujeres tuvieron dos causas principalmente: buscar trabajo (29.3 por ciento) y reunirse con su familia (29.7 por ciento). Esto puede referirse a que migra un miembro de la familia primero y en lo que se estabiliza económicamente puede trasladar a su familia para vivir juntos, lo que indica la fortaleza que toman las redes sociales en la migración hacia Nuevo León (Figura 4).

La migración como una oportunidad para vencer las desigualdades del lugar de origen se ve reflejada en aquellos que llegan a Nuevo León a estudiar o a trabajar y estudiar a la misma vez. En el caso de las mujeres en el año 2000, 9.3 por ciento migraron para estudiar. Esta misma cantidad de mujeres ( 9.3 por ciento) migraron para unirse a su pareja en Nuevo León.

Para el año 2014 la Encuesta de la Dinámica Demográfica revela varios cambios en las causas de la migración de hombres y mujeres hacia la entidad de Nuevo León. En el caso de los hombres, la principal causa sigue siendo buscar trabajo 39.6 por ciento, mientras que para las mujeres perdió representatividad, pasando de 29.3 por ciento en 2000 a 25.9 por ciento en 2014 (Figura 5).

La reunificación familiar es una de las causas que más representatividad ganó en el año 2014, 27 de cada 100 hombres y 43 de cada 100 mujeres migran para reunificarse con su familia.

Las estrategias familiares de reunificación permiten que no solo el migrante logre mejorar económicamente al conseguir un empleo, sino que pueda conseguir mejores oportunidades de desarrollo para toda su familia. Como lo afirmó Stark desde La Nueva Economía, la decisión de migrar no es tomada por actores individuales, sino también pone un énfasis en las estrategias familiares para superar las imperfecciones del mercado en regiones de origen (Stark, 1993).

Aunque no es una causa principal por la que llegan las personas a Nuevo León, es importante mencionar que la inseguridad llega a casi cinco por ciento tanto en hombres como en mujeres, lo que indicaría un leve aumento de la migración forzada hacia Nuevo León.

\section{Estructura por sexo y edad de la población inmigrante}

La Figura 6 permite analizar la distribución de la población migrante por estructura de edad y sexo para 1990, 2000, 2010 y 2015. Aunque la base de la pirámide no es la mayoría de la población migrante, de manera general se observa una reducción progresiva de esta población, específicamente en edades de 5 a 9 años y de 10 a 14 años, esto 
como resultado de la reducción de la fecundidad, efecto que se da no solo en la población migrante sino también en la población en general de Nuevo León.

La dinámica demográfica de la población migrante que ha llegado a Nuevo León en los últimos 25 años muestra una selectividad, tanto de las mujeres como de los hombres en edades de 15-64 años, edades en la que los migrantes acceden al mercado laboral.

Se observa que el grupo de edad con mayor concentración de población en el periodo de estudio es el de 20-24 años, el cual ha venido aumentando considerablemente en cada periodo, con preponderancia masculina en el 2015 (Figura 6), los hombres de 20 a 24 años pasaron de representar el 10.2 por ciento de la población migrante en 1990, a 13.7 por ciento en 2015. Este rasgo de las poblaciones migrantes internas en México había sido mencionado por Sobrino (2016), aseverando que la máxima intensidad migratoria se da en edades entre 20-29 años tanto en hombre como en mujeres, edades productivas.

En cuanto al protagonismo de las mujeres migrantes en edades productivas en el periodo de estudio 1990-2015, el grupo que tiene mayor representatividad son las mujeres de 15-19 años que representan 11.7 por ciento de los migrantes en 1990. De manera general se puede observar en la pirámide que, a partir de los cuarenta años, la representación de las mujeres y los hombres es muy similar y con tendencia a disminuir década tras década.

\section{Educación}

La desigualdad en México también se manifiesta en el acceso a la educación. La brecha educacional está ligada al nivel de desarrollo de los lugares de origen. Aunque a nivel nacional la educación básica es casi universal, aún muchas personas no tiene acceso a la escuela (INEGI, 2018).

Aunque las teorías clásicas de la migración exponen que son las personas más preparadas en el lugar de origen las que tienen mayor oportunidad de migrar, en la Figura 7 se puede observar que la población analfabeta sigue migrando hacia Nuevo León, esto porque como se verá más adelante, los perfiles de los migrantes en Nuevo León varían ampliamente por ocupación.

Los datos censales para México muestran que de 1990 a 2010 el porcentaje de población de 15 años y más que no sabía leer y escribir pasó de 25.8 a 6.9 por ciento (INEGI). 
Figura 6. Nuevo León. Estructura por edad y sexo de la población migrante 1990-2015

1990

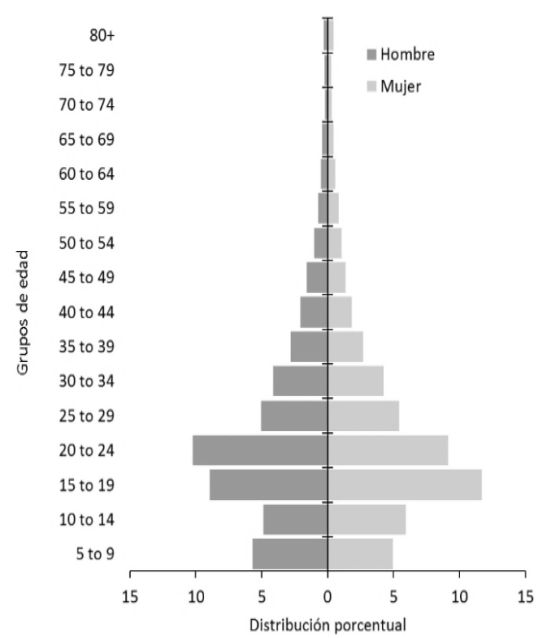

2010

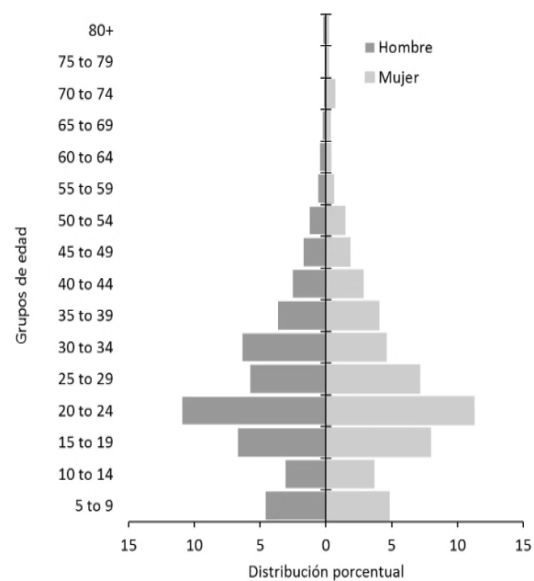

2000

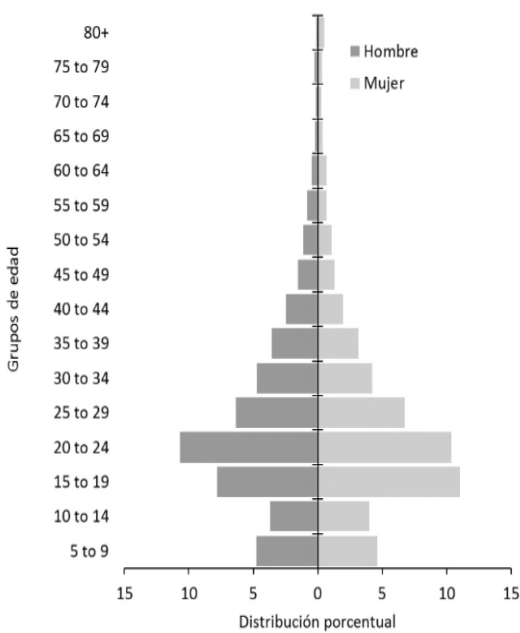

2015

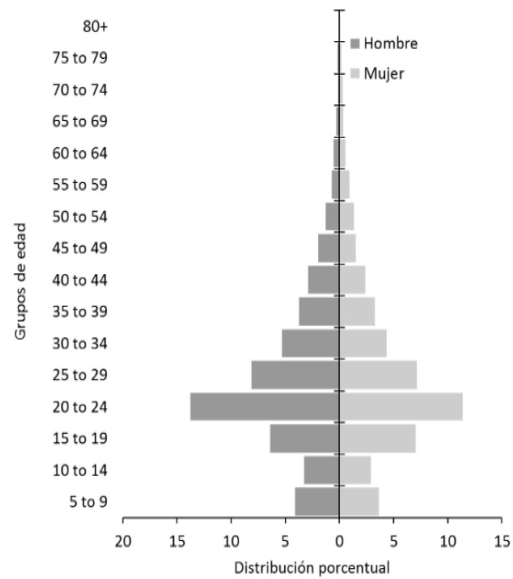

Fuente: elaboración propia con base en datos censales 1990, 2000 y 2010 y Encuesta Intercensal 2015 del INEGI.

En 1990 aproximadamente diez por ciento de la población que llegó a Nuevo León proveniente de Zacatecas y San Luis Potosí eran analfabetas. Para el año 2000, el analfabetismo fue reduciéndose, en esta década 7.4 por ciento de población analfabeta provino de Durango. Los datos de 2015 revelan que es Veracruz la entidad que reciente- 
mente expulsa más población analfabeta hacia Nuevo León, alcanzado casi cuatro por ciento.

Figura 7. Tasa de analfabetismo de migrantes por entidad de origen 1990-2015

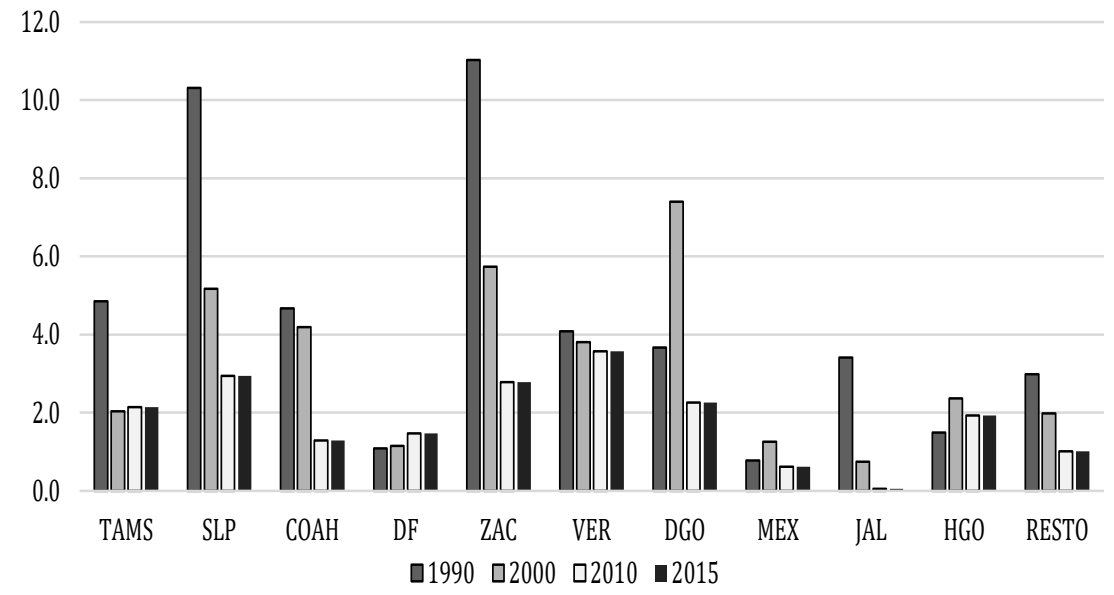

Fuente: elaboración propia con base en datos censales 1990, 2000 y 2010 y Encuesta Intercensal 2015 del INEGI.

La Figura 8 presenta el nivel de escolaridad por sexo de los migrantes que llegaron a Nuevo León en el periodo de estudio. Tanto para hombres como para mujeres migrantes en 1990 y 2000 el nivel de escolaridad más representativo fue la primaria. Mientras que a partir de 2010 la secundaria fue el nivel de escolaridad con más representatividad.

Un análisis con perspectiva de género de los migrantes que llegan a Nuevo León, evidencia que han sido las mujeres las que han superado mayormente las brechas de desigualdad educativa. Los datos revelan que en 1990 sólo 8.5 por ciento de las mujeres que llegaban a Nuevo León contaban con preparatoria, pero en 2010 alcanzaban 17 por ciento, un avance educacional de las mujeres que se vé reflejado en las ocupaciones que vienen a desarrollar en la entidad. En cuanto al nivel de preparatoria de los hombres migrantes, en 1990 fue de 10.8 por ciento y alcanzó 22.7 por ciento, en 2015.

En 1990, 21 por ciento de los hombres que llegaron a Nuevo León eran profesionales, cifra que no ha variado mucho en los últimos 25 años, puesto que en 2015 alcanzaron 20.4 por ciento de hombres migrantes profesionales. En cuanto a las mujeres para 1990 sólo 10.8 por 
ciento de las migrantes llegaron a la entidad con estudios profesionales, en 2015, 17 por ciento de migrantes contaban con estos estudios. De modo que la educación ha empezaso a dar a las mujeres algunas ventajas competitivas en la inserción laboral.

Figura 8. Nivel de escolaridad de hombres y mujeres que migraron a Nuevo León 1990-2015

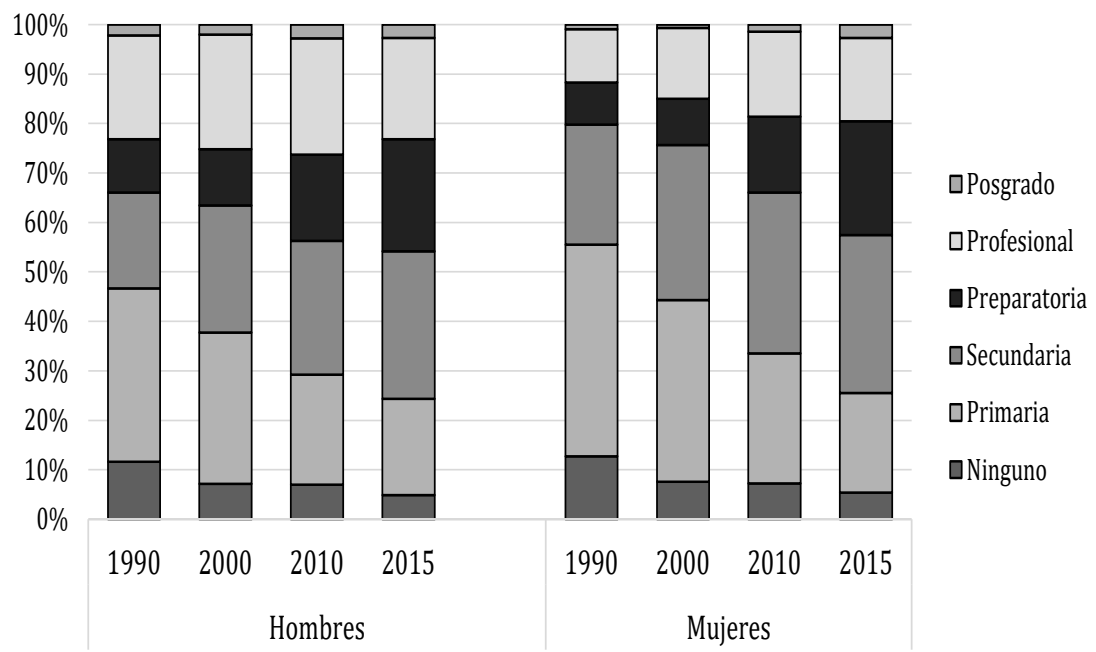

Fuente: elaboración propia con base en datos censales 1990, 2000 y 2010 y Encuesta Intercensal 2015 del INEGI.

\section{Una comparación entre la situación laboral de migrantes y no migrantes}

La condición de actividad de una población refleja la capacidad que tiene esa sociedad para emplear y generar productividad en la mano de obra disponible. Al comparar la población migrante y no migrante, encontramos una diferencia significativa, los datos revelan que para 1990, 64 por ciento de los hombres migrantes trabajaban contra 70 por ciento de los no migrantes. Y es en 1990 cuando se presenta la mayor cantidad de desempleados migrantes alcanzando casi 30 por ciento. También llama la atención que el número de jubilados o pensionados no migrantes es de casi el doble que los migrantes, esto va relacionado con que los migrantes internos llegan en edades jóvenes para insertarse al mercado laboral. 
Estudios de la migración indican las diferencias que se encuentran en la actividad laboral de los migrantes al diferenciarlos por sexo (Urquidi, 1970, Albers, 1977 y Partida, 1994). Pero en el caso de las mujeres, los porcentajes de su participación en la economía son sumamente similares (Figura 9).

Figura 9. Nuevo León. Comparación de condición de actividad laboral entre hombres migrantes y no migrantes 1990-2015

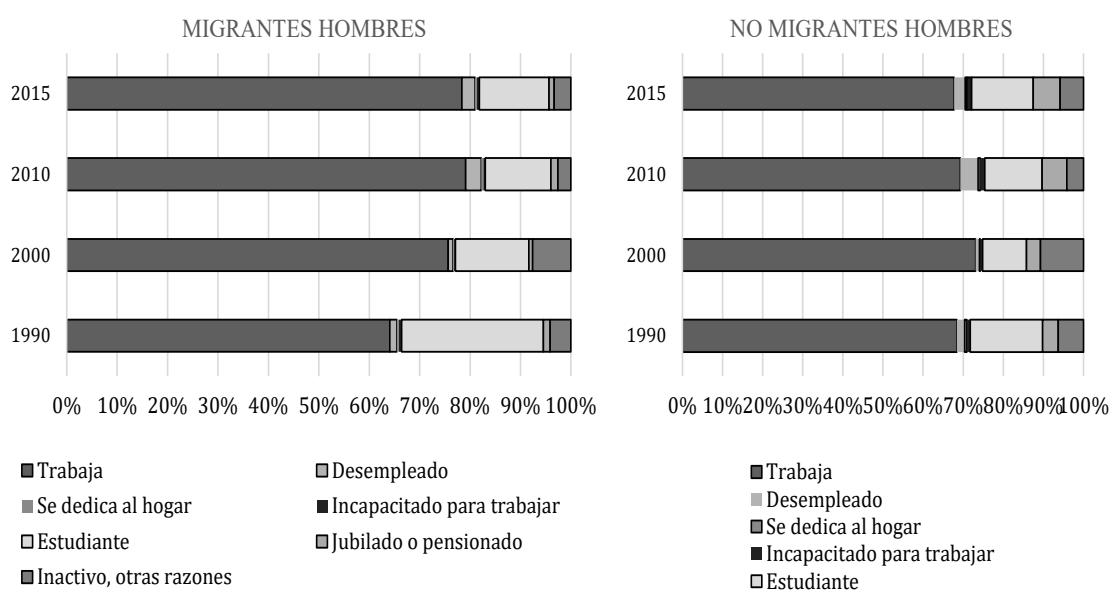

Fuente: Elaboración propia con base en datos censales 1990, 2000 y 2010 y Encuesta Intercensal 2015 del INEG

De las mujeres que migraron a Nuevo León en 1990 destaca que 27 por ciento de ellas trabajabajaron, mientras que para 2015 su fuerza laboral aumenta a 41.4 por ciento.

También es importante mencionar que 20 por ciento de las mujeres que llegaron a Nuevo León en 1990, venían a estudiar. Mientras que 50 por ciento hacían parte de la población de arrastre, aquella población que acompaña al trabajador migrante, en este caso 50 por ciento de las mujeres que se dedicaban a los quehacer del hogar. Es hasta el año 2000 cuando las mujeres migrantes representan aún más la fuerza laboral de Nuevo León, alcanzando 40 por ciento de mujeres trabajadoras (Figura 10). De modo que se puede demostrar que, en las últimas décadas la migración ha sido una estrategia claramente familiar, donde las mujeres asumian el rol de apoyo en el cuidado de los hijos y los quehaceres del hogar mientras el padre de familia salía a trabajar. 
Figura 10. Nuevo León. Comparación de condición de actividad laboral entre mujeres migrantes y no migrantes 1990-2015

\section{MIGRANTES MUJERES}

2015

2010

2000

1990

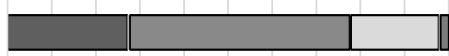

$0 \% 10 \%$ 20\% 30\% 40\% 50\% 60\% 70\% 80\% 90\%100\%

\section{- Trabaja}

$\square$ Se dedica al hogar

$\square$ Estudiante

口Inactivo, otras razones

\section{NO MIGRANTES MUJERES}

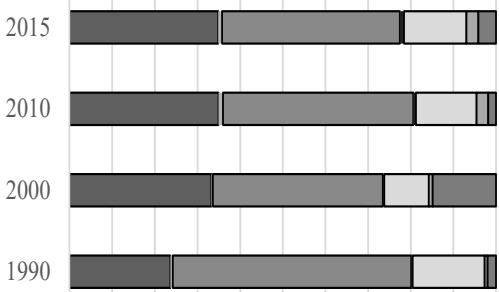

$0 \%$ 10\% 20\% 30\% 40\% 50\% 60\% 70\% $80 \%$ 90\% $100 \%$

口Trabaja $\quad$ Desempleado

$\square$ Se dedica al hogar $\quad$ Incapacitado para trabajar

$\square$ Estudiante $\quad \square$ Jubilado o pensionado

口Inactivo, otras razones

Fuente: elaboración propia con base en datos censales 1990, 2000 y 2010 y Encuesta Intercensal 2015 del INEGI.

La teoría de la segmentación del mercado de trabajo definida por Castles y Kosack (1984), permite comprender como la migración trae consigo segmentación, fragmentación de clase y nuevas formas de estratificación social y económica.

En esta investigación se analiza si hay segmentación laboral en la población migrante interna en comparación con la población no migrante. Se analizan no solo los trabajos no cualificados también, los puestos de trabajo cualificados que son ocupados por migrantes. La Tabla 3 presenta el índice de disimilitud de Duncan, este índice permite comparan proporciones de dos grupos, en este caso las ocupaciones de migrantes con respecto a los no migrantes en Nuevo León.

Tabla 3. Segregación ocupacional en Nuevo León

\begin{tabular}{ccc}
\hline Índice de Disimilitud (ID) & A dos dígitos & En porcentaje \\
\hline 1990 & 0.16 & 15.6 \\
2000 & 0.19 & 18.7 \\
2010 & 0.18 & 17.6 \\
2015 & 0.16 & 16.3 \\
\hline
\end{tabular}

Fuente: elaboración propia con base en datos censales 1990, 2000 y 2010 y Encuesta Intercensal 2015 del INEGI. 
Se observa que la segregación ocupacional ${ }^{3}$ se ha mantenido en los últimos veinticinco años, en 1990 el indicador de 0.16 significa que 16 por ciento de la población migrante debería reubicarse en ocupaciones distintas para que la distribución de los migrantes y los no migrantes se asemeje. Para el año 2000 el índice alcanza 0.19 por ciento reflejando un leve aumento en la segregación. Aunque podría pensarse que la disimilitud entre migrantes y no migrantes es mínima, es importante resaltar que ha estado presente en los últimos 25 años y que en Nuevo León el lugar de origen y las características físicas de un migrante pueden pesar más que la preparación académica o las competencias laborales para insertarse en un empleo.

Al calcular el Índice de Duncan ${ }^{4}$ se tiene como resultado que, en Nuevo León, los migrantes han estado sobrerrepresentados en el periodo de estudio de 1990-2015 en ocupaciones de baja cualificación como: trabajadores en protección, operadores de maquinaria fija y equipos industriales, ayudantes, peones y similares y trabajadores domésticos.

La Tabla 4 revela que la población de Nuevo León se ha desempeñado en los últimos 25 años principalmente en cuatro ocupaciones: Oficinistas, comerciantes y agentes de ventas, obreros y artesanos y operadores de maquinaria fija. Para conocer el comportamiento del mercado de trabajo de la población migrante y no migrante en la Tabla 4 se presenta esta comparación, se decidió clasificar las casi 500 ocupaciones en 18 grupos, para resaltar aquellos donde la población migrante de Nuevo León tradicionalmente ha tenido mayor participación.

De la población no migrante destaca que en el caso de los obreros y artesanos pasaron de ser 18 por ciento en 1990 a 10 por ciento en 2015, podría afirmarse que la población no migrante se fue especializando y los técnicos ganaron peso, pasando de 4.1 por ciento en 1990 a 10.6 por ciento en 2015 . Los profesionales también han mostrado un aumento importante en 1990, 3.6 por ciento era profesional en 2015, 8.7 por ciento pudieron ocuparse como profesionales.

Los trabajadores domésticos aumentan en la población no migrante reciente, representaban tan solo 3 por ciento en 1990 y se duplica-

3 Para este análisis se define la segregación ocupacional como la selectividad a determinadas ocupaciones que pueden llegar a experimentar los migrantes.

4 Si a la distribución porcentual de las ocupaciones de los migrantes le restamos la de los no migrantes podemos ver en qué ocupaciones hay mayor selectividad y así calcular en índice de Duncan 
ron a 6.6 por ciento en 2015, esto explicado tal vez por aquellas personas migrantes que llegaron a Nuevo León hace más de cinco años para ocuparse en trabajados domésticos y llevan años en esta ocupación sin haber regresado a sus lugares de origen.

Tabla 4. Nuevo León. Comparación de ocupaciones entre migrantes y no migrantes 1990-2015

\begin{tabular}{|c|c|c|c|c|c|c|c|c|}
\hline \multirow{2}{*}{ Ocupación } & \multicolumn{4}{|c|}{ Migrantes } & \multicolumn{4}{|c|}{ No migrantes } \\
\hline & 1990 & 2000 & 2010 & 2015 & 1990 & 2000 & 2010 & 2015 \\
\hline Funcionarios y directivos & 5.8 & 5.4 & 4.9 & 2.4 & 3.9 & 3.3 & 3.0 & 2.3 \\
\hline Jefes administrativos & 2.3 & 2.6 & 3.4 & 2.0 & 2.6 & 3.0 & 3.4 & 2.6 \\
\hline Jefes y supervisores de fabrica & 2.6 & 3.5 & 2.9 & 2.6 & 3.3 & 3.1 & 2.6 & 2.2 \\
\hline Profesionales & 4.9 & 5.4 & 7.7 & 8.1 & 3.6 & 4.6 & 6.6 & 8.7 \\
\hline Oficinistas & 6.6 & 5.7 & 4.9 & 5.7 & 10.4 & 9.9 & 7.8 & 8.5 \\
\hline Técnicos & 2.8 & 3.0 & 7.7 & 8.0 & 4.1 & 4.0 & 12.4 & 10.6 \\
\hline Comerciante & 8.9 & 8.6 & 10.5 & 9.6 & 9.8 & 13 & 14.7 & 12.9 \\
\hline Trab & 3.7 & 2.2 & 1.0 & 1.4 & 3.8 & 3.6 & 2.5 & 3.1 \\
\hline táculo y & 1.1 & 1.0 & 1.2 & 0.9 & 0.9 & 0.9 & 0.9 & 1.0 \\
\hline serv. personales & 4.9 & 5.7 & 5.4 & 5.2 & 5.0 & 6.0 & 4.1 & 4.8 \\
\hline & 4.7 & 2.5 & 2.9 & 4.9 & 3.3 & 2.3 & 2.6 & 2.7 \\
\hline Trab & 3.4 & 2.9 & 2.0 & 0.5 & 5.3 & 2.9 & 1.5 & 1.2 \\
\hline Obre & 16.3 & 14.4 & 10.2 & 9.6 & 18.1 & 17.2 & 11.1 & 9.8 \\
\hline Oper & 6.8 & 10.5 & 8.4 & 13.8 & 8.8 & 9.9 & 6.9 & 8.6 \\
\hline Operadores de transporte & 3.3 & 3.0 & 4.4 & 4.5 & 5.9 & 6.5 & 7.5 & 7.6 \\
\hline Ayı & 7.8 & 6.1 & 8.4 & 8.2 & 6.2 & 4.3 & 4.4 & 4.3 \\
\hline Trabajadores ambulantes & 2.1 & 1.1 & 1.2 & 1.9 & 1.8 & 1.9 & 1.4 & 2.5 \\
\hline Trabajadores domésticos & 12.2 & 16.4 & 12.9 & 10.7 & 3.0 & 3.6 & 6.4 & 6.6 \\
\hline Total & 100.0 & 100.0 & 100.0 & 100.0 & 100.01 & 100.0 & 100.0 & 100.0 \\
\hline
\end{tabular}

Fuente: elaboración propia con base en datos censales 1990, 2000 y 2010 y Encuesta Intercensal 2015 del INEGI.

En cuanto a los migrantes internos, se han ocupado principalmente como obreros y artesanos siendo 1990 el año donde alcanzaron su mayor ocupación en esta actividad 16.3 por ciento disminuyendo en 2015 a 9.6 por ciento de lado de esto ha ganado protagonismo los migrantes que se emplean como operadores de maquinaria fija y operadores de maquinaria industrial, pasando de 6.3 por ciento en 1990 a 13.8 por ciento en 2015 , lo que indica una tecnificación de los procesos industriales de la región (Tabla 4).

En el caso de los migrantes, los datos revelan que para el año 2000 solo 5.4 por ciento se desempeñaba como profesionistas, alcanzando en $2015,8.1$ por ciento. Igualmente, los técnicos toman un papel más protagónico en las ocupaciones desempeñadas en 2015 alcanzando 8 por ciento. 


\section{Perfiles ocupacionales de migrantes internos}

A continuación, se analizan las características principales de la población migrante ocupada para el periodo de estudio 1990-2015. Recurriendo a los microdatos censales de este periodo de estudio, primero se presenta la magnitud de la población ocupada, luego se analizan los cuatro grupos de ocupaciones creadas, en relación con la entidad de origen, sexo y escolaridad.

La Figura 11 refleja lo que al principio de este apartado se mencionó, el crecimiento de la población ocupada en Nuevo León se ha duplicado en los últimos 25 años. Para conocer si realmente ha habido un cambio ocupacional de la población migrante, se crean estos cuatro grandes grupos de ocupaciones, donde se distinguen ocupaciones manuales y no manuales de alta y baja calificación.

Figura 11. Nuevo León. Grupos de ocupaciones de migrantes internos 1990-2015

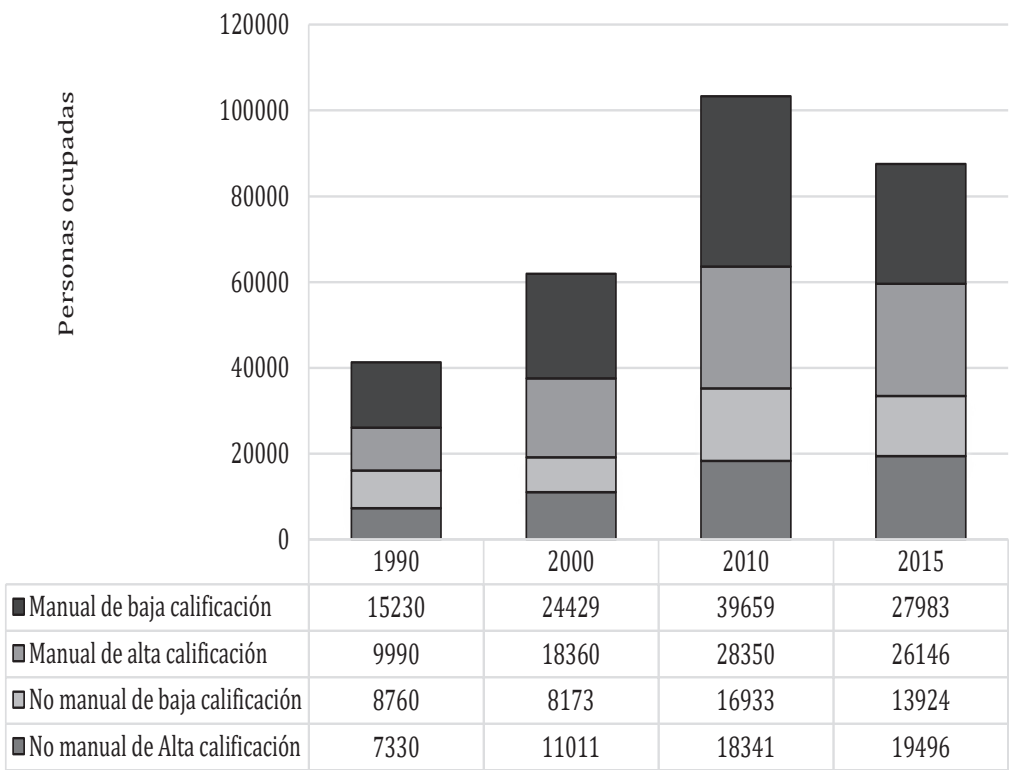

Fuente: elaboración propia con base en datos censales 1990, 2000 y 2010 y Encuesta Intercensal 2015 del INEGI.

Los datos revelan que Nuevo León es un polo de atracción de empleos variados, y que los migrantes principalmente llegan a ocupar cargos manuales de baja calificación, dentro de estos encontramos: 
trabajadores en servicios personales y domésticos, trabajadores en actividades elementales. De 1990 a 2010 la proporción de migrantes que se desempeñaron en actividades manuales de baja cualificación casi se triplicó, pero en la última década se observa cómo el mercado laboral da oportunidades a migrantes insertados en empleos no manuales de alta calificación, pasando de 7,330 migrantes en 1990 a 19,496 migrantes en 2015, cifra casi triplicada en veinticinco años. Dentro de estos están los operadores de maquinaria industrial y los trabajadores artesanales.

Como se mencionó al principio de este capítulo las principales entidades que expulsaron migrantes hacia Nuevo León en el periodo de estudio 1990-2015 fueron Tamaulipas, San Luis Potosí, Coahuila y Veracruz. Las figuras de la 12 a la 15 permiten conocer de qué entidad migraron las personas ocupadas en estos cuatro grandes grupos de ocupaciones.

Los migrantes que se han desempeñado en ocupaciones no manuales de alta calificación como lo son profesionales, técnicos, jefes y directivos para 1990 provenían en 23 por ciento de ciudad de México, 18 por ciento de Tamaulipas y 11 por ciento de Coahuila (Figura 12).

Figura 12. Nuevo León. Ocupación no manual de alta calificación de migrantes 1990-2015

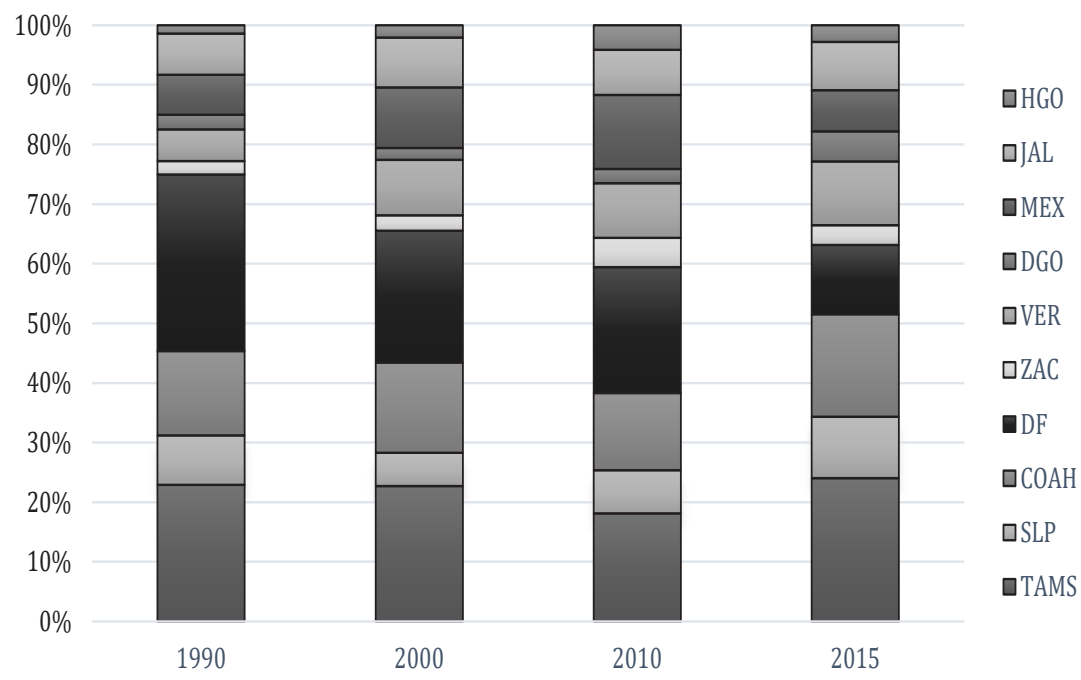

Fuente: elaboración propia con base en datos censales 1990, 2000 y 2010 y Encuesta Intercensal 2015 del INEGI 
Es importante mencionar que muchas de las matrices de grandes y medianas empresas se encuentran en Ciudad de México, por lo que la migración entre Ciudad de México y Nuevo León podría estar ligada a transferencias, traslados y promociones laborales para ofrecer mejores oportunidades para el desarrollo del migrante interno en Nuevo León.

En cuanto a los migrantes que se ocuparon en empleos no manuales de baja calificación como los trabajos en actividades administrativas, los comerciantes y los vendedores (Figura 13) para 1990 provenían principalmente de Tamaulipas con 22 por ciento y Ciudad de México, 16 por ciento. En el año 2000 empiezan a tomar protagonismo los empleados migrantes no manuales de baja calificación de entidades como Veracruz, pasando de 4.3 por ciento en 1990 a 15.3 por ciento en 2015 (Figura 13).

Figura 13. Nuevo León. Ocupación no manual de baja calificación de migrantes 1990-2015

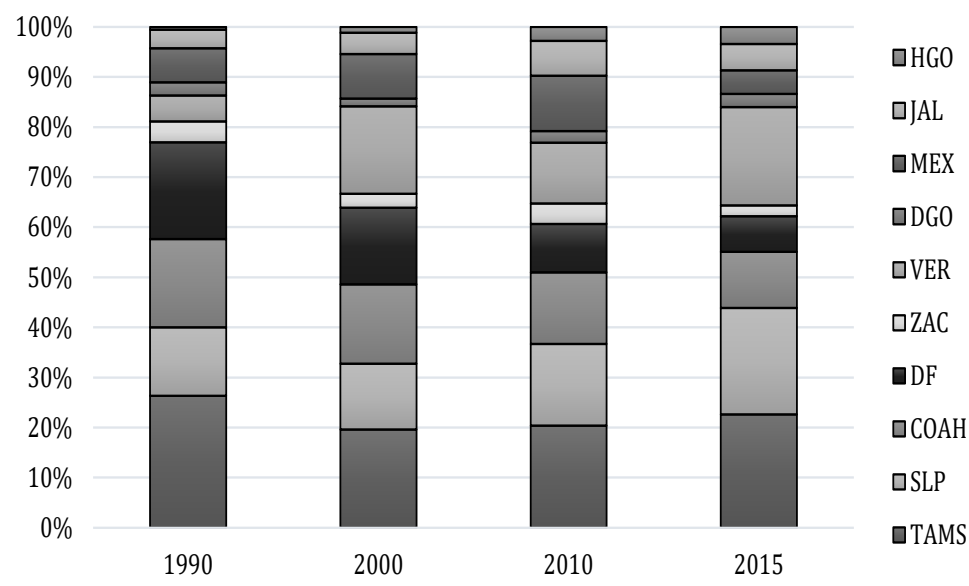

Fuente: elaboración propia con base en datos censales 1990, 2000 y 2010 y Encuesta Intercensal 2015 del INEGI.

En las ocupaciones manuales de alta calificación como lo son los operadores de maquinaria industrial y los trabajares artesanales, la Figura 14 resalta que estas ocupaciones han sido ocupadas por migrantes provenientes de San Luis Potosí y de Veracruz. Para Ciudad de México se dio un comportamiento inverso pues en 1990 el 16 por ciento de estas ocupaciones eran asumidas por personas de esta entidad federativa disminuyendo hasta 5.6 por ciento en 2015 . 
Figura 14. Nuevo León. Ocupación manual de alta calificación de migrantes 1990-2015

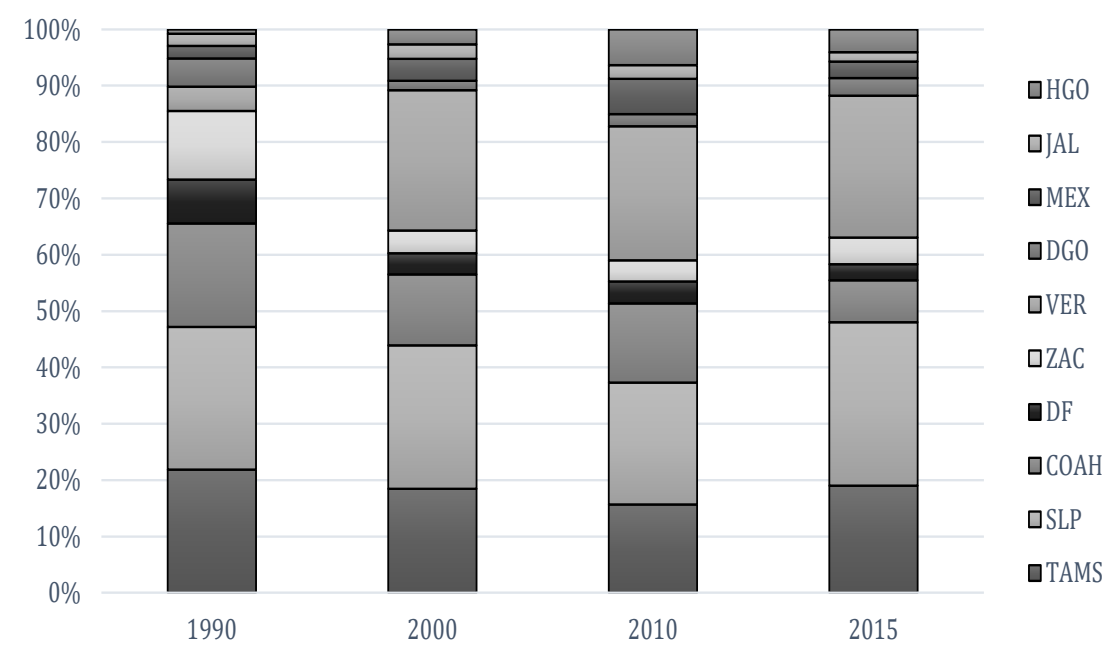

Fuente: Elaboración propia con base en datos censales 1990, 2000 y 2010 y Encuesta Intercensal 2015 del INEGI.

Figura 15. Nuevo León. Ocupación manual de baja calificación de migrantes 1990-2015

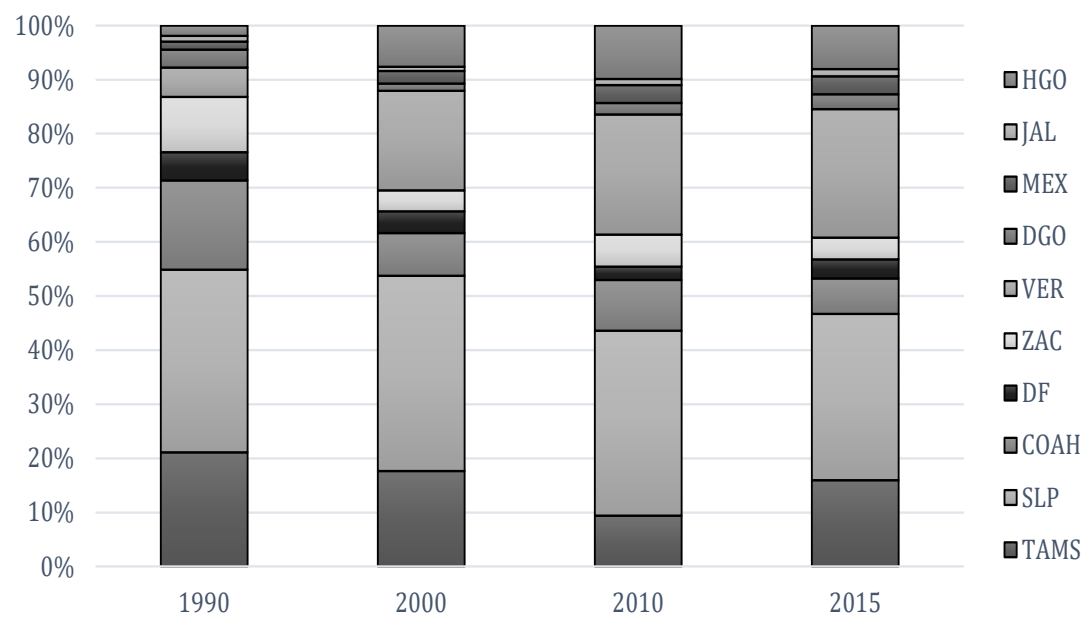

Fuente: elaboración propia con base en datos censales 1990, 2000 y 2010 y Encuesta Intercensal 2015 del INEGI. 
De las ocupaciones manuales de baja calificación hacen parte los trabajadores en actividades elementales, los trabajadores en servicios personales y los trabajadores agrícolas, estos empleos han sido desempeñados en Nuevo León los últimos veinticinco años principalmente por migrantes provenientes de San Luís Potosí (Figura 15).

Los migrantes provenientes de Tamaulipas que se emplearon en ocupaciones manuales de baja calificación pasaron de 19 por ciento en 1990 a 9 por ciento en 2010. Aunque llegaron más migrantes a Nuevo León provenientes de Veracruz, pasando de representar cinco por ciento en 1990 a 19.5 por ciento en 2015 .

La Figura 16 permite verificar a lo largo del periodo de estudio si la población migrante se inserta en determinadas ocupaciones dependiendo del sexo. En los últimos 25 años, las mujeres migrantes se han desempeñado principalmente en trabajos manuales de baja calificación tales como trabajadoras domésticas, comerciantes, oficinistas, operadoras de maquinaria industrial fija. Mientras que los hombres han estado representados en trabajos manuales de alta y baja calificación como por ejemplo artesanos y obreros, operadores de maquinaria fija, ayudantes de diferentes labores, peones y comerciantes.

Figura 16. Nuevo León. Comparación de hombres y mujeres migrantes en cuatro grupos de ocupaciones 1990-2015

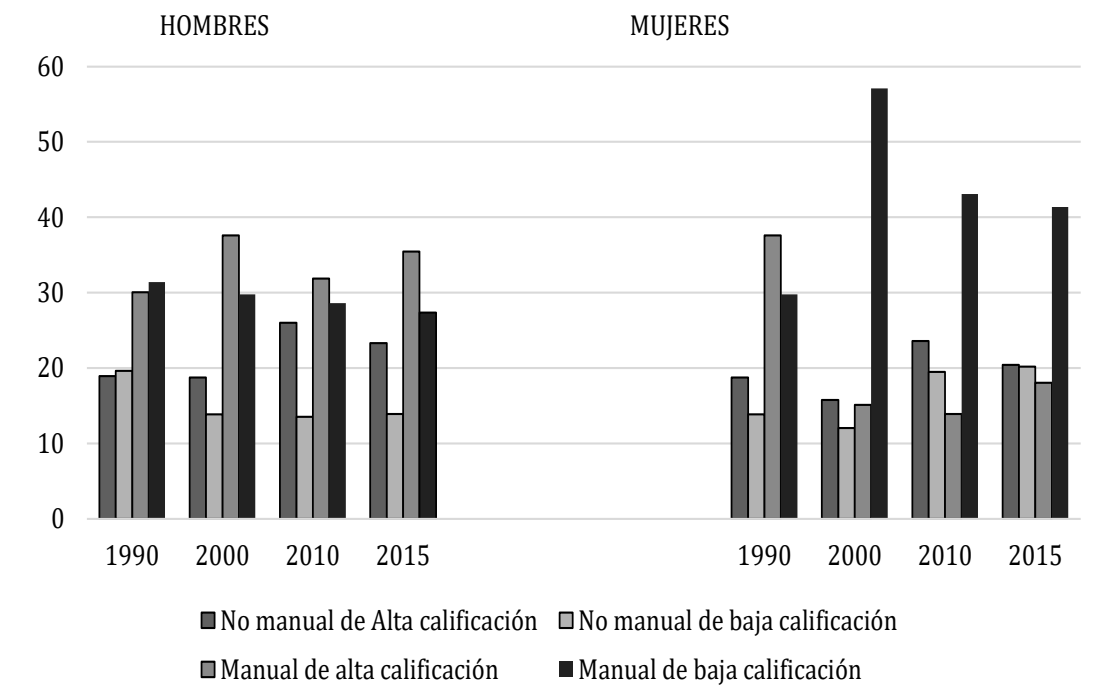

Fuente: elaboración propia con base en datos censales 1990, 2000 y 2010 y Encuesta Intercensal 2015 del INEGI. 
Es de esperarse que la inversión en capital humano que hacen las personas se vea reflejada en las ocupaciones que desempeñan, pero también es cierto que muchas veces ser profesional o especialista en un área, no garantiza ocuparse inmediatamente en lo que se desea.

Las figuras 17 y 18 presentan los porcentajes de las actividades que desempeñan los migrantes que llegan a Nuevo León clasificadas en cuatro grupos de ocupaciones: No manual de alta calificación, No manual de baja calificación, Manual de alta calificación y Manual de baja calificación.

Figura 17. Nuevo León. Grupos de ocupación por escolaridad 1990-2000

1990

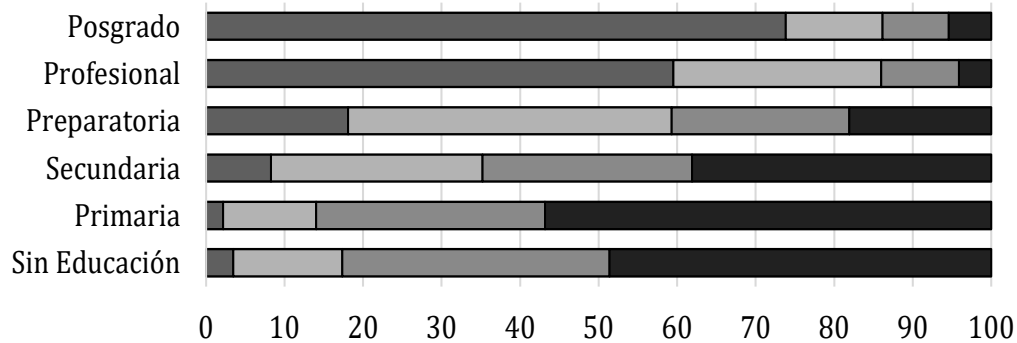

$\square$ No manual de Alta calificación $\square$ No manual de baja calificación

$\square$ Manual de alta calificación

-Manual de baja calificación

2000

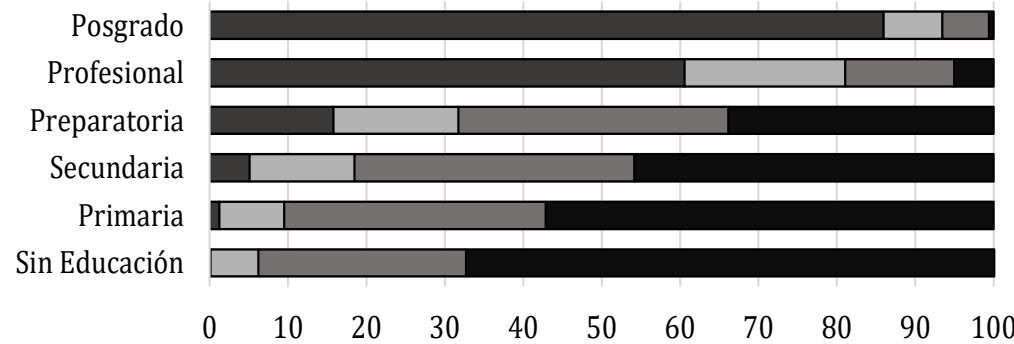

๑No manual de Alta calificación $\square$ No manual de baja calificación

$\square$ Manual de alta calificación $\quad$ Manual de baja calificación 
Figura 18. Nuevo León. Grupos de ocupación por escolaridad 2010-2015

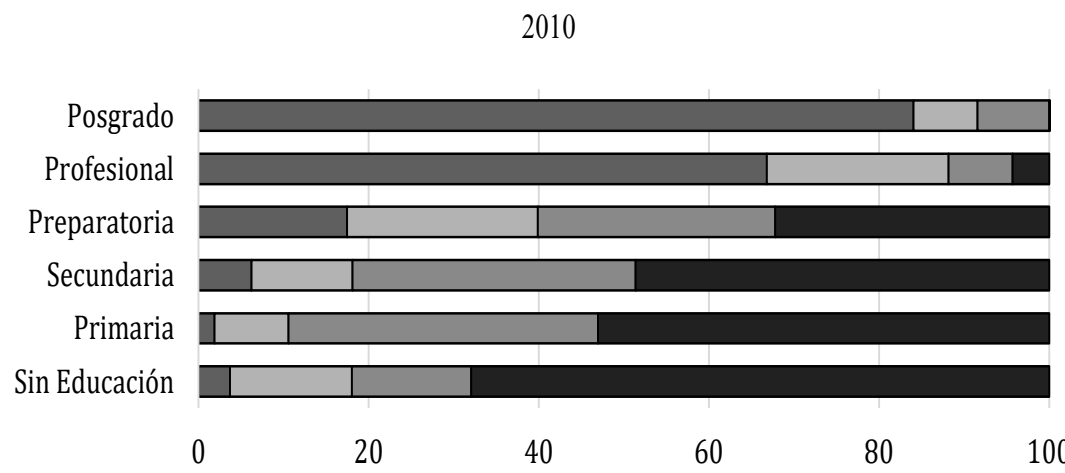

口No manual de Alta calificación $\square$ No manual de baja calificación

口Manual de alta calificación \Manual de baja calificación

2015

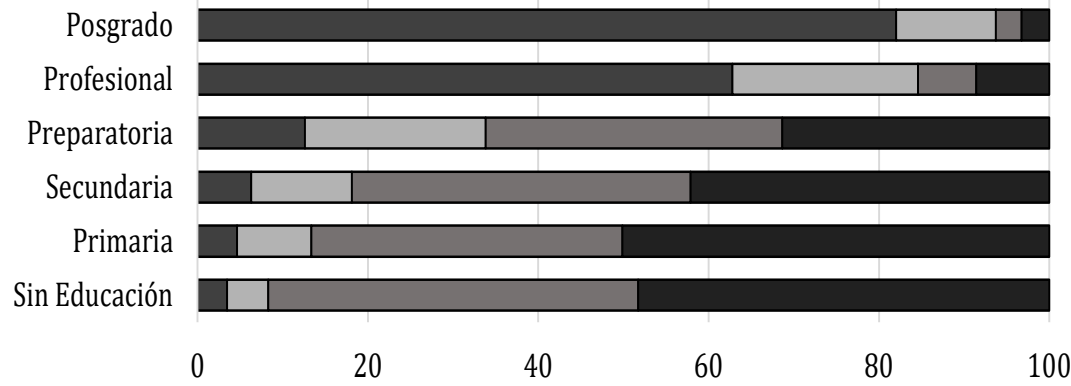

口No manual de Alta calificación $\square$ No manual de baja calificación

口Manual de alta calificación $\quad$ Manual de baja calificación

Fuente: elaboración propia con base en datos censales 1990, 2000 y 2010 y Encuesta Intercensal 2015 del INEGI.

El 50 por ciento de los migrantes que no tenían estudios o cursaron solo la primaria en 1990 se desempeñaron en trabajos manuales de baja calificación, tales como trabajadores en actividades elementales y trabajadores en servicios personales. De la misma forma, en 1990 contar con la preparatoria también llevaba a los migrantes internos 
a desempeñarse principalmente en ocupaciones no manuales de baja cualificación, entre estas ocupaciones se encuentran trabajadores auxiliares en actividades administrativas, comerciantes y vendedores.

Analizando a aquellos migrantes que tienen nivel de estudio profesional, los datos revelan que para el año 2000 hay menos desigualdad en el acceso a las ocupaciones por escolaridad con la que se cuenta los migrantes. El 61 por ciento de los profesionistas acceden a trabajos no manuales de alta calificación, como lo son profesionistas y técnicos, funcionarios, directivos, jefes y supervisores, otro 21 por ciento hace parte de los trabajos no manuales de baja calificación como lo son: trabajadores auxiliares en actividades administrativas, comerciantes y vendedores, 18 por ciento restante de migrantes profesionales se desempeñan en ocupaciones manuales.

Comparando las cifras de 1990 con las de 2010, en la Figura 17, en 2010 los migrantes sin educación se han desempeñado en casi 70 por ciento en ocupaciones de manuales de baja cualificación, esto está indicando que en Nuevo León cada vez se hace más importante la educación para que los migrantes puedan acceder a mejores puestos de trabajo.

En 2015 destaca una mayor distribución de los empleos en aquellas personas con estudios inferiores a secundaria, esto porque aproximadamente 50 por ciento de ellos se desempeñaron en ocupaciones manuales de baja cualificación y el otro 50 por ciento lograron acceder a ocupaciones manuales de alta calificación y ocupaciones no manuales.

\section{CONCLUSIONES}

Los resultados obtenidos permiten visibilizar que la migración interna hacia Nuevo León ha presentado un aumento absoluto de los migrantes recientes y aun cuando el migrante que sigue llegando a la entidad es joven, aumenta su promedio de edad, pasando de 25.7 años en 1990 a 27.5 años en el 2015. En cuanto a su lugar de origen, estos migrantes provienen de entidades vecinas como San Luis Potosí, Tamaulipas y Coahuila. En las últimas décadas, las mejoras en el transporte y la comunicación han permitido que los migrantes lleguen de lugares más lejanos de la república mexicana, se han consolidado nuevos flujos migratorios, que han venido ganando fuerza, es el caso de migrantes provenientes de Veracruz, Ciudad de México e Hidalgo. 
Los motivos para migrar hacia Nuevo León principalmente son laborales: buscar trabajo o cambiarse de trabajo, algunos otros migran por motivos de reunificación familiar y de estudio.

Una de las características que más han cambiado en los últimos veinticinco años en los migrantes internos que llegan a Nuevo León es la escolaridad, y es que el promedio de años de estudio del migrante que llegaba en 1990 era de 7.2 años de estudio pasando al 2015 a 9.8 años. Superando además a los no migrantes de la entidad. Este resultado va ligado al aumento en la población en edad de trabajar, y la disminución de población menor de edad, cambios demográficos importantes reflejados no solo en la entidad sino en la población a nivel nacional.

De modo que en Nuevo León se confirma la tesis de que las propensiones a migran de algunos migrantes se elevan cuando se tiene un nivel de educación mayor que el resto de la población nativa, ya que se puede acceder más fácilmente a ofertas laborales y se encuentra calificado para tener mejor puestos y mejores salarios que los no migrantes.

Estos cambios han sido consecuentes con el acceso al mercado de trabajo en la entidad. Pero es importante aclarar que en Nuevo León no existe solo un perfil migratorio, la globalización trajo consigo cambios en los procesos económicos nacionales y locales y la demanda de mano de obra es diversificada, por tanto, existen perfiles migratorios que se han adaptado a este cambio.

Como lo indicó Sassen (1993), la migración es un sistema de suministro de mano de obra adecuado a las necesidades de las empresas con ciertas formas de organización que incluyen un control que presupone la ineficacia del trabajo con bajos salarios. Y es que a Nuevo León siguen llegando migrantes a ocupar puestos de trabajo flexibles y con remuneraciones bajas, propias del sistema neoliberal que impera en el país.

Estos resultados nos plantean que es importante no descuidar el estudio de la migración interna en México, pues es la forma como las poblaciones reconfiguran la estructura demográfica y social del país. Queda pendiente en el estudio de las migraciones en México análisis comparativos de las principales entidades receptoras de migrantes, conocer si los perfiles migratorios han cambiado considerablemente en todos los polos de atracción del país y que dinámicas se mueven en torno a la segregación y selectividad migratoria laboral. 


\section{REFERENCIAS BIBLIOGRÁFICAS}

Alarcón, D. (2001). Documento de trabajo. Washington: Banco Interamericano de Desarrollo, Serie de Documentos de Trabajo I-21.

Alba, F. (1979). La población de México, evoluciones y dilemas. México: El Colegio de México.

Balán, J., Browning, H. \& Jelin, E. (1973). Migración, estructura ocupacional y movilidad social. México: Universidad Nacional Autónoma de México.

Canales, A. (2015). E pur si muove. Guadalajara: Miguel Ángel Porrua.

Castles, S. \& Kosack, G. (1984). Los trabajadores inmigrantes y la estructura de clases en Europa Occidental.. México: Fondo de cultura económica.

Chávez, A. M. (1999). La nueva dinámica de la migración interna en México de 1970 a 1999. Cuernavaca: Centro Regional de investigaciones multidisciplinarias, UNAM.

Consejo Nacional de Población (CONAPO), (2019). Geografía Migratoria. disponible en: https://www.conapo.gob.mx/es/CONAPO/Geografia_Migratoria

Faist, T. (2010). The crucial meso-level. En: Selected Studies in International Migration and Immigrant Incorporation. Amsterdam: Amsterdam University Press, pp. 59-90.

Garza, G. (1999). Monterrey en el contexto de la globalización. En: La globalización en Nuevo León. San Nicolás: El Caballito.

Gurak, D. \& Caces, F. (1998). Redes Migratorias y la formación de sistemas de migración. En: Cruzando Fronteras. Barcelona: Editorial Icaria.

Instituto Nacional de Estadística y Geografía (INEGI), (1990). XI Censo General de Población y Vivienda 1990, disponible en: https://www.inegi.org.mx/programas/ccpv/1990/

Instituto Nacional de Estadística y Geografía (INEGI), (2000). XII Censo General de Población y Vivienda 2000, disponible en https://www.inegi.org.mx/programas/ccpv/2000/

Instituto Nacional de Estadística y Geografía (INEGI), (2010). Censo de Población y Vivienda 2010, disponible en https://www.inegi.org.mx/programas/ccpv/2010/

Instituto Nacional de Estadística y Geografía (INEGI), (2014), Encuesta Nacional de la Dinámica Demográfica (ENADID) 2014. disponible en https://www.inegi. org.mx/programas/enadid/2014/

Instituto Nacional de Estadística y Geografía (INEGI), (2015), Encuesta Intercensal 2015, disponible en https://www.inegi.org.mx/programas/intercensal/2015/

Lee, E. (1966). A Theory of Migration. Demography, pp. 47-57. 
Lewis, A. (1960). Desarrollo Ilimitado con oferta ilimitada de mano de obra. México: Fondo de Cultura Económica.

Macció, G. A. (1985). Diccionario Demográfico Multilingüe: Versión en Español. Lieja, Béljica: Ediciones Ordina.

Massey, D. (1990). Social structure, household strategies and the cumulative causation of migration. Population Index 56.

Ortega, I. (2007). La industrialización: del segundo auge industrial a la crisis de 1982. Monterrey: Fondo Editorial de Nuevo León.

Partida, V. (1994). Migración interna. Aguascaliente: INEGI, UNAM.

Pérez, E. (2006). Reestructuración urbano-regional y emigración de la ZMCM. México: Tesis para obtener el grado de Doctor en Geografía, UNAM.

Perez, E., \& Santos, C. (2008). Urbanización y migración entre ciudades, 1995-2000. Un análisis multinivel. Papeles de Población, pp 173-214.

Portes, A. \& Böröcz, J. (1998). Migración contemporánea. Perspectivas teóricas sobre sus determinantes y sus modalidades de incorporación. En: Cruzando Fronteras. Barcelona: Editorial Icaria, pp. 43-73.

Ravenstein, E. (1885). The Laws of Migration. Journal of the Statistical Society of London, pp. 167-235.

Rodríguez, J. (2016). Migración y distribución espacial de la población. Santiago : CEPAL.

Sánchez, J., Luyando, J. Aguayo, E. \& Picazzo, E. (2014). El desarrollo laboral sustentable y su relación con la migración interna en México. Región y sociedad, pp. 29-61.

Sassen, S. (1993). La Movilidad del trabajo y del capital. Madrid: Ministerio de trabajo y seguridad social.

Sobrino, J. (2010). Migración interna en México. México, df: Consejo Nacional de Población.

Sobrino, J. (2016). Migración interna en México, 1995-2015. Coyuntura demográfica, Issue 10, pp. 57-65.

Stark, O. (1993). La migración del trabajo. Madrid: Ministerio de Trabajo y Asuntos Sociales.

Todaro, M. (1982). Economía para un mundo en desarrollo. México: Fondo de cultura económica.

Valero, J. \& Tijerina, J. (1998). Inmigración al área metropolitana de Monterrey, salarios, empleo y ocupación, 1985-1996. En: Economía regional y migración. Monterrey: Universidad de Guadalajara, Asociación Mexica de Población A.C., Juan Pablos Editor, pp. 19-111. 


\section{RESUMEN CURRICULAR DE LA AUTORA}

Yuliet Bedoya Rangel

Socióloga por la Universidad del Valle de Cali, Colombia y Doctora en Ciencias Sociales con orientación en desarrollo sustentable por la Universidad Autónoma de Nuevo León. Realizó su estancia doctoral en la Comisión Económica para América Latina de las Naciones Unidas en Santiago de Chile en 2016. Actualmente es becaria del Programa de Becas Posdoctorales en la UNAM, en El Centro Regional de Investigaciones Multidisciplinarias CRIM, asesorada por el Dr. Fernando Lozano Ascencio. Miembro de la Red Migrare y la Red Latinoamericana de Estudios Fronterizos (RELATEF); colaboradora del proyecto Humanizando la deportación de la UC Davis. Sus líneas de investigación han sido: Migración interna e internacional, remesas internacionales y calidad de vida, de las cuales ha publicado diversos artículos en revistas arbitradas y ha participado en eventos académicos de difusión científica a nivel nacional e internacional.

Dirección electrónica: yulietbedoya@gmail.com; yulietbedoya@crim. unam.mx

Registro ORCID: https://orcid.org/0000-0002-1974-6377 